\title{
Classification of Sea Ice Types in the Arctic by Radar Echoes from SARAL/AltiKa
}

\author{
Renée Mie Fredensborg Hansen ${ }^{1,2}, *$ (D) , Eero Rinne ${ }^{1(D)}$ and Henriette Skourup ${ }^{2}$ (D) \\ 1 Marine Research, Finnish Meteorological Institute, P.O. Box 503, 00101 Helsinki, Finland; eero.rinne@fmi.fi \\ 2 Geodesy and Earth Observation, DTU Space, Elektrovej, Building 327, 2800 Kgs. Lyngby, Denmark; \\ hsk@space.dtu.dk \\ * Correspondence: renee.fredensborg@fmi.fi
}

Citation: Fredensborg Hansen, R.M.; Rinne, E.; Skourup, H. Classification of Sea Ice Types in the Arctic by Radar Echoes from SARAL/AltiKa. Remote Sens. 2021, 13, 3183. https:// doi.org/10.3390/rs13163183

Academic Editors: Juha Karvonen and Anton Korosov

Received: 28 June 2021

Accepted: 1 August 2021

Published: 11 August 2021

Publisher's Note: MDPI stays neutral with regard to jurisdictional claims in published maps and institutional affiliations.

Copyright: (c) 2021 by the authors. Licensee MDPI, Basel, Switzerland. This article is an open access article distributed under the terms and conditions of the Creative Commons Attribution (CC BY) license (https:// creativecommons.org/licenses/by/ $4.0 /)$.

\begin{abstract}
An important step in the sea ice freeboard to thickness conversion is the classification of sea ice types, since the ice type affects the snow depth and ice density. Studies using Ku-band CryoSat-2 have shown promise in distinguishing FYI and MYI based on the parametrisation of the radar echo. Here, we investigate applying the same classification algorithms that have shown success for Ku-band measurements to measurements acquired by SARAL/AltiKa at the Ka-band. Four different classifiers are investigated, i.e., the threshold-based, Bayesian, Random Forest (RF) and $k$-nearest neighbour (KNN), by using data from five 35 day cycles during Arctic mid-winter in 2014-2018. The overall classification performance shows the highest accuracy of 93\% for FYI (Bayesian classifier) and 39\% for MYI (threshold-based classifier). For all classification algorithms, more than half of the MYI cover falsely classifies as FYI, showing the difference in the surface characteristics attainable by Ka-band compared to Ku-band due to different scattering mechanisms. However, high overall classification performance (above 90\%) is estimated for FYI for three supervised classifiers (KNN, RF and Bayesian). Furthermore, the leading-edge width parameter shows potential in discriminating open water (ocean) and sea ice when visually compared with reference data. Our results encourage the use of waveform parameters in the further validation of sea ice/open water edges and discrimination of sea ice types combining Ka- and $\mathrm{Ku}$-band, especially with the planned launch of the dual-frequency altimeter mission Copernicus Polar Ice and Snow Topography Altimeter (CRISTAL) in 2027.
\end{abstract}

Keywords: SARAL/AltiKa; radar echoes; classification; MYI; FYI; radar altimetry; sea ice types

\section{Introduction}

Sea ice affects the Earth's climate and recent studies show a decline in the ice formation, distribution and volume in the Arctic [1]. The sea ice in the Arctic has experienced significant changes, with the average extent of sea ice cover in the summer declining by 43\% between 1979 and 2019 while continuing to become younger and thinner than in 1980-2000s [2]. Sea ice is a key parameter in the climate system because the increasing warming of the atmosphere results in a further reduction in sea ice [3]. With the reduced sea ice extent and thickness, the ocean absorbs more heat and increases the air temperatures, resulting in inhibited sea ice formation and lowering of the albedo, also known as the ice-albedo feedback [4]. Through the recent global climate model's, it is projected that the ice-albedo feedback will be a major contributor to the expected increase in warming [5]; thus, it is critical to monitor the changes in sea ice extent, distribution of ice types and sea ice thickness. Sea ice thickness data have previously been acquired by upward-looking sonar mounted on submarines and moorings (e.g., [6,7]) and electromagnetic induction sensors mounted on airborne platforms (e.g., [8,9]). While these observations are regionally and spatially limited, satellite altimetry (radar altimetry, in particular) provides near-global elevation measurements that contain information of surface roughness depicted as altimetric radar echoes from which the elevation of sea ice thickness can be inferred [1]. 
Sea ice has been monitored since the beginning of the 1980s by radar altimetry missions. Many of the dedicated ocean altimetry missions do not possess high enough orbit inclination for Arctic sea ice observations. However, there has been a series of pulse-limited European Ku-band radar altimeters providing measurements up to 81.5 degrees North (i.e., ERS-1, ERS-2 and Envisat). More recently, satellites carrying synthetic aperture radar (SAR) altimeters have been launched: CryoSat-2, Sentinel-3A and Sentinel-3B. The along-track SAR processing provides finer resolution in the along-track direction than conventional pulse limited altimeters ( $\sim 300 \mathrm{~m}$ in contrast to several kilometres). With the launch of the French-Indian (Centre National D'Etudes Spatiales (CNES)/Indian Space Research Organisation (ISRO)) Satellite with ARgos and AltiKa (SARAL) on 25 February 2013, the first altimeter mission carrying a pulse-limited Ka-band radar (AltiKa) was initiated (see more details below and in Section 2). An overview of all altimeter missions covering the Arctic Ocean, including former, present and future missions, is provided in overview Table 1, and more information can be found in Quartly et al. [10], Kern et al. [11] and Markus et al. [12].

Table 1. Performance characteristics of Altimeters covering the Arctic ocean including former, present and future missions. In particular, three major types of missions are presented: Light Detection and Ranging (LiDAR) laser altimeter missions, low-resolution-mode (LRM; conventional, pulse-limited) altimeter missions and synthetic aperture radar (SAR) altimeter missions.

\begin{tabular}{lllllll}
\hline Mission & Organisation & Mission Period & Altimeter & Type & Frequency Band & Coverage \\
\hline GEOS-3 & NASA & $1974-1979$ & RA & LRM & $\mathrm{Ku}$ & 72.0 \\
SeaSat & NASA & 1978 & RA & LRM & $\mathrm{Ku}$ & 72.0 \\
Geosat & US Navy & $1985-1989$ & RA & LRM & $\mathrm{Ku}$ & 72.0 \\
ERS-1 & ESA & $1991-2000$ & RA & LRM & $\mathrm{Ku}$ & 81.5 \\
ERS-2 & ESA & $1995-2003$ & RA & LRM & $\mathrm{Ku}$ & 81.5 \\
Envisat & ESA & $2002-2012$ & RA-2 & LRM & $\mathrm{Ku} / \mathrm{S}$ & 81.5 \\
ICESat & NASA & $2003-2009$ & GLAS & LiDAR & Optical $(1064 / 532 \mathrm{~nm})$ & 86.0 \\
CryoSat-2 & ESA & $2010-$ & SIRAL & SAR & $\mathrm{Ku}$ & 88.0 \\
SARAL & CNES/ISRO & $2013-$ & AltiKa & LRM & $\mathrm{Ka}$ & 81.5 \\
Sentinel-3A & ESA & $2016-$ & SRAL & SAR & $\mathrm{Ku} / \mathrm{C}$ & 81.5 \\
Sentinel-3B & ESA & $2018-$ & SRAL & SAR & $\mathrm{Ku} / \mathrm{C}$ & 81.5 \\
ICESat-2 & NASA & $2018-$ & ATLAS & LiDAR photons & Optical $(532 \mathrm{~nm})$ & 88.0 \\
Sentinel-3C & ESA & $\sim 2021-$ & SRAL & SAR & $\mathrm{Ku} / \mathrm{C}$ & 81.5 \\
Sentinel-3D & ESA & $\sim 2023-$ & SRAL & SAR & $\mathrm{Ku} / \mathrm{C}$ & 81.5 \\
CRISTAL & ESA & $\sim 2027-$ & IRIS & SAR & $\mathrm{Ku} / \mathrm{Ka}$ & 88.0 \\
\hline
\end{tabular}

The classification of surface types including sea ice types is part of the algorithm for determining sea ice thickness by freeboard-to-thickness conversion [1,13-16], and it is also important for operational ice charting [17]. Radar echoes (waveforms) have been studied since the early heritage missions (GEOS-2, SeaSat, GeoSat and ERS-1/2) in the 1980's (e.g., [18,19]). Dwyer and Godin [18] observed that altimeter radar waveforms have higher power values over smooth sea ice than over the rough open ocean, suggesting possible discrimination between the sea ice and the open ocean. Fedor et al. [20] observed a reduction in the signal response when comparing flat to ridged sea ice, and Fetterer [21] observed the strongest return signal from leads (calm, open water or thin ice between ice floes), producing specular echo power waveforms. With these findings, the possibility of retrieving information on sea ice and sea ice type classification from radar altimeter data has been discussed in several studies (e.g., [22-24]). Currently, sea ice thickness retrieval algorithms only employ a method for distinguishing leads from ice floes to estimated freeboard, which is the sea ice above local sea surface level [25], but recent studies have investigated the possibility of discriminating between sea ice types with airborne [15] and spaceborne SAR radar altimeters $[17,26-28]$. The assumptions are based on the shape of the waveform from conventional altimeters acquired over ice and snow to characterise the underlying surface in order to differentiate based on the sea ice type. Sea ice in the 
Arctic can be divided into two major groups: first-year ice (FYI) and multi-year ice (MYI). The surface characteristics of these ice types differ due to, e.g., accumulation, convergence and survival of the melting season, causing MYI to generally have a rougher surface [29]. Normally, FYI radar echoes will have a high peak value of backscatter and a steep decay as the surface is relatively smooth with thin snow cover, thus primarily experiencing surface scattering. In comparison, MYI (and heavily deformed FYI) will often exhibit lower backscatter and a slower decay [27]. While recent studies have investigated spaceborne Ku-band SAR altimeters (CryoSat-2) (e.g., $[17,27,28]$ ), there have been no such studies investigating the possibility of discriminating sea ice types from spaceborne Ka-band radar altimeters, to the best of our knowledge. Thus, we will investigate the possibility in this paper.

AltiKa is the first satellite altimeter operating in Ka-band (see [30] and Table 1). The higher frequency offers higher spatial resolution, resulting in potentially better lead detection than conventional Ku-band altimeters [30]. Furthermore, it permits less penetration into the snow cover that is covering the sea ice compared with earlier Ku-band missions [31]. Moreover, the volume echo in the Ka-band is a result of the near subsurface layer and is more sensitive to ice grain size than Ku-band [32]. With its relatively high orbit coverage $\left(81.5^{\circ} \mathrm{N}\right)$, one of the objectives of AltiKa is to study continental ice and sea ice. Successful use of satellite altimeters to estimate sea ice types will provide users with an independent validation product for other sea ice type products (e.g., Ocean and Sea Ice Satellite Application Facility (OSI SAF)), as well as a potential estimate of the sea ice edge. It will also provide direct input for the altimetry derived freeboard-to-thickness conversion and improve the estimates of sea ice thickness [26]. In addition, acquiring this information from the same platform and instrument as the freeboard/thickness measurement itself will reduce the uncertainty due to the lack of temporal latency, which is usually introduced between the altimeter measurement and the related sea ice type mask obtained by other sources.

In this paper, we will investigate several approaches that classify sea ice into MYI and FYI (including deformed sea ice) based on former studies on CryoSat-2 Ku-band radar altimetry. We show that different sea ice types produce significantly different shapes of radar echoes represented by five selected waveform parameters. Our study areas are selected by visual inspection of OSI SAF sea ice type products. The influence of snow cover and radar penetration will be briefly discussed. Finally, a reference to the European Space Agency (ESA)'s future polar altimetry mission, The Copernicus Polar Ice and Snow Topography Altimeter (CRISTAL) is provided.

This paper is divided as follows: Section 2 describes the SARAL/AltiKa altimeter data and the used reference data. The parametrisation of the echo waveform is described in Section 3, as well as pre-processing of data, classification method and discrimination of surface types. The evaluation of the classification performance and of the results is shown in Section 4 and the discussion is presented in Section 5. In Section 6, the conclusion is presented.

\section{Data}

\subsection{SARAL/AltiKa}

We use waveforms from SARAL's main instrument, AltiKa. More specifically, we use the geophysical data records (GDR) data set provided by the CNES data centre: Archiving, Validation and Interpretation of Satellites Oceanographic (AVISO). The data were acquired in February and March ( 35 days; a similar period as the repeat cycle of AltiKa) every year between 2014 and 2018. 
SARAL was launched on 25 February 2013 and AltiKa was first switched on 26 February with the first cycle beginning on 14 March. SARAL flies on a similar orbit as Envisat did, with an inclination of $98.55^{\circ}$ providing coverage up to $81.55^{\circ} \mathrm{N}$. The orbit is sunsynchronous with a 35-day repeat cycle. AltiKa operates in a single-frequency band of $37.5 \mathrm{GHz}$, which is the Ka-band, and thus possesses reduced ionospheric effects when compared with Ku-band [33]. The higher frequency results in a smaller footprint of $8 \mathrm{~km}$ (compared to Envisat's $20 \mathrm{~km}$ ). This combined with AltiKa's higher pulse repetition frequency compared to that of Envisat ( $4 \mathrm{kHz}$ for AltiKa) results in better along-track sampling. Furthermore, the enhanced bandwidth $(480 \mathrm{MHz})$ enables a better range resolution $[14,30,32,33]$.

\subsection{OSI SAF Sea Ice Type}

For selecting study areas we use sea ice type charts from Ocean and Sea Ice Satellite Application Facility (OSI SAF). The sea ice type product of the European Organisation for the Exploitation of Meteorological Satellites (EUMETSAT) OSI SAF is available at www. osi-saf.org (accessed on 29 July 2021). The ice classes are assigned from atmospherically corrected Special Sensor Microwave Imager/Sounder (SSMIS) brightness temperatures $(19 \mathrm{H}, 19 \mathrm{~V}, 37 \mathrm{~V}, 91 \mathrm{H}$ and $91 \mathrm{~V}$, where $\mathrm{H}$ and $\mathrm{V}$ note horizontal and vertical polarisation, respectively) and Advanced SCATterometer (ASCAT) (C-band) backscatter values onboard EUMETSAT platform Metop-A and Metop-B, by using a Bayesian approach. The sea ice types are provided in a grid with a resolution of $10 \mathrm{~km}$ spacing on a Polar Stereographic projection and possess a time span of $24 \mathrm{~h}$. The sea ice types utilise the OSI SAF sea ice edge product to define the border between sea ice and open water, using a threshold of $30 \%$ of ice concentration $[34,35]$. For this study, days with the maximum sea ice extent are chosen to visually recognise specific FYI and MYI areas as training data sets. Furthermore, data from OSI SAF sea ice types from February 2014 to 2018 have been extracted in order to compare with the classified AltiKa data, i.e., data from each day of the month have been combined and averaged to create a monthly ice type chart for February for each of the specified years.

\section{Method}

In this study, we aim to use AltiKa altimeter data to discriminate between FYI and MYI. The ice types usually have different surface characteristics, i.e., FYI is relatively smooth as it is newly formed ice whereas MYI appears rougher due to its age and is more deformed by accumulation and redistribution. This difference can be used to discriminate between the different sea ice types $[14,15]$, as different waveform shapes depict the different surface characteristics. We extract five waveform parameters here (see Section 3.1) from the radar echoes and investigate a simple classification approach based on thresholds (Section 3.3.1) and three supervised classifiers (Sections 3.3.2-3.3.4). In order to determine unbiased thresholds, pre-processing is a necessary step (Section 3.2), e.g., to remove data affected by leads.

\subsection{Parametrisation of Waveforms}

In order to classify sea ice types from AltiKa, we investigate five waveform parameters as described below and shown schematically in Figure 1. 


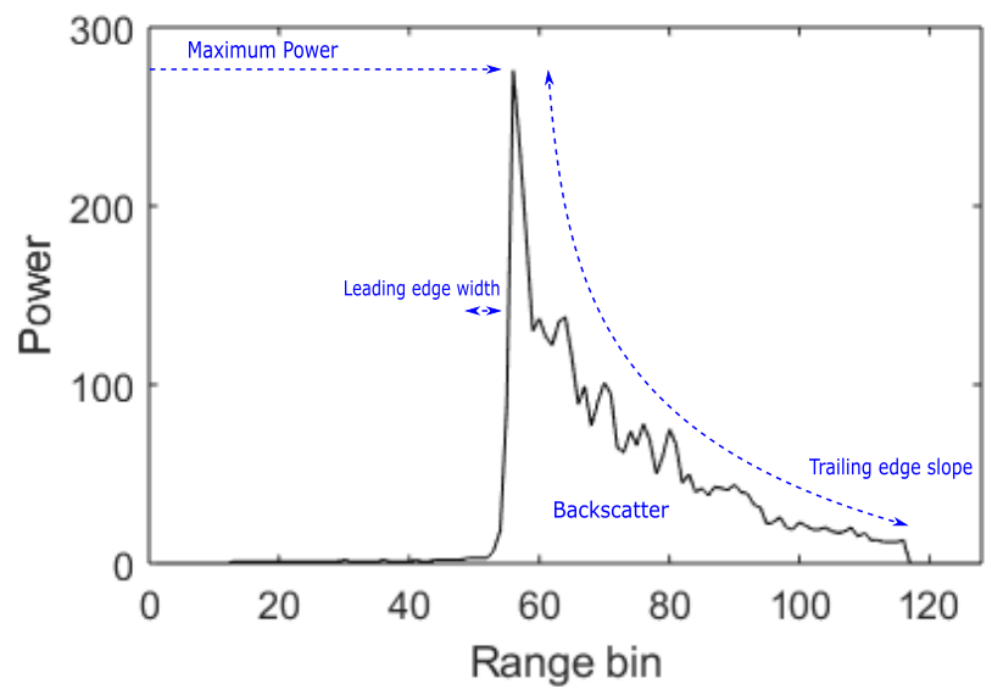

Figure 1. Schematic visualisation of different features (parameters) of a radar altimeter waveform.

- Maximum power (MAX) is the highest recorded power in the calibrated waveform. It has been used in several studies to identify sea ice leads (e.g., $[1,13,14])$ and characterises, in general, the reflective properties of the surface [14]. Zakharova et al. [14] formulated the expression to calculate MAX for AltiKa:

$$
M A X=10 \cdot \log _{10}\left(\max \left(P_{i}\right) \cdot 10^{\frac{A G C}{10}}\right),
$$

where $A G C$ is an automatic gain control (in $\mathrm{dB}$ ) and $P_{i}$ is the power in the ith bin.

- Pulse peakiness (PP) describes the specularity of the radar echo return (high PP near surfaces with high reflectances, such as FYI or leads $[14,15,26])$ and was first defined by Laxon [24] for ERS-1. For AltiKa GDR data, PP must, as described in Zakharova et al. [14], be calculated as follows:

$$
P P_{A l t i K a}=\frac{\max \left(P_{i}\right) \cdot N_{\text {right }}}{\sum_{i=1}^{N_{W F}} P_{i}},
$$

where $N_{W F}$ is the total number of gates, i.e., 128 , and $N_{\text {right }}$ is the number of points to the right of the bin containing the MAX value.

- The leading-edge-width (LEW) is defined as the width between 1 and $99 \%$ of the amplitude of a Gaussian fit to the leading edge of a waveform [13]. For specular returns (leads), LEW will be smaller than for scattered returns (e.g., MYI) [15]. LEW is available in the AltiKa data product from the ICE-2 retracker and is directly used in this study.

- $\quad$ Research has shown that the trailing edge slope (TES) is a parameter useful for distinguishing between MYI and FYI with Ku-band radar altimeters while being highly correlated with the trailing edge width (TEW) [15]. TES is defined as the decay factor for the exponential fit [36]. There is a clear difference in the decay after the peak of the waveform when comparing MYI and FYI, as MYI generally has a lower decay rate (with a wider TEW) than FYI (and leads) [15]. TES is available in the AltiKa data product from the ICE-2 retracker.

- The backscatter coefficient $\left(\sigma_{0}\right)$ is computed from the power of the returned pulse and provides information about the surface from which the pulse has been reflected. MYI has lower backscatter values due to the rougher surface caused by, e.g., deformation, allowing MYI to scatter the pulse away from the radar at nadir, whereas FYI experiences more specular returns due to less deformation; thus, the return signal from nadir will be stronger [33]. The backscatter coefficient from AltiKa can be obtained from the retracking algorithms ICE-1, ICE-2 and SEA ICE [37]. Rajkumar et al. [33] argues 
that retracking algorithms ICE-1 and SEA ICE have similar backscatter observations over sea ice, indicating great suitability for sea ice observations, whereas the bias with ICE-2 retracker was apparent for the backscatter observations. Therefore, in this study, instead of using the backscatter coefficient from the ICE-2 retracker as is used when retrieving LEW and TES, the backscatter coefficient obtained from the SEA ICE retracker is used.

\subsection{Pre-Processing of Altika Data}

The pre-processing of AltiKa data is necessary to reduce the amount of data that could impact the results. First, the specific study areas are defined (see Figure 2 for specifications).

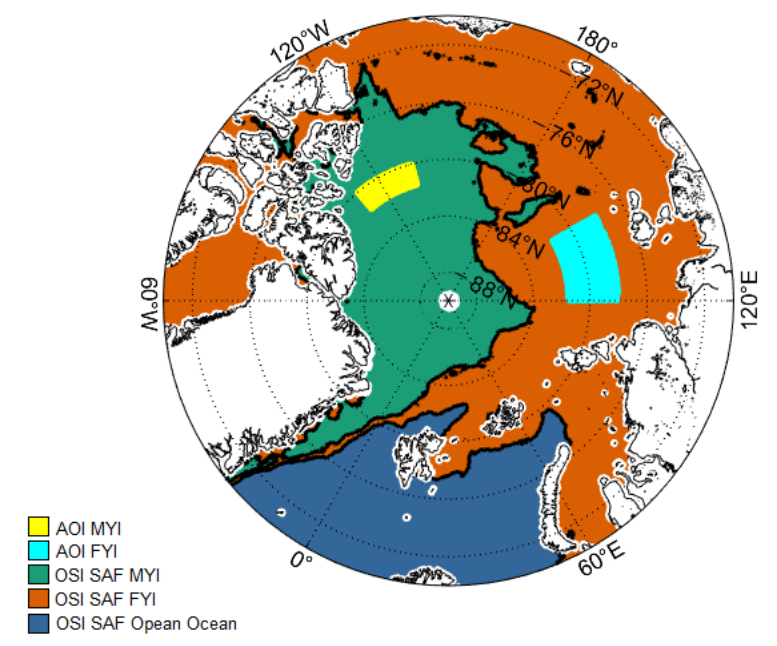

Figure 2. Map of the study areas by area of interest (AOI) chosen by visual inspection of Ocean and Sea Ice Satellite Application Facility (OSI SAF) sea ice types. AOI first-year ice (FYI) is shown in yellow and AOI multi-year (MYI) in cyan. Averaged ( $\sim 30 \mathrm{~d}$ ) OSI SAF sea ice type map from February 2016 is applied as the background representing MYI in green, FYI in brown and open ocean in dark blue. Dark lines denote FYI/MYI border and ice/ocean edge, respectively.

The locations are based on the simple assumption that one area is covered by FYI and the other by MYI and that these areas are representative for the two types of sea ice present in the Arctic. Any points outside these areas have been removed from the initial processing. Next, filtering by the surface type flag and ice flag provided in the AltiKa GDR is applied. We only keep radar echoes measured over what is defined as ocean surface and ice.

\section{Discrimination between Specular and Diffuse Waveforms}

Identifying whether waveforms are specular or diffuse renders it possible to discriminate between measurements of calm ocean surface (leads) and ice surfaces [25]. When a radar burst is reflected from a smooth, mirror-like surface, e.g., leads or very calm ocean, a specular echo occurs. In a case such as this, the power in the range window rises and falls again very rapidly, creating a narrow echo. Diffuse echoes occur when the radar burst is scattered from a rougher surface, e.g., deformed sea ice, where the echoes become less peaky compared to specular returns from the calm water [16]. Examples of waveforms from specular and diffuse echoes are shown in Figure 3.

In order to identify specular and diffuse echoes, it is common to use thresholds for PP as described in Section 3.1. Studies of CryoSat-2 have used different thresholds for PP values to discriminate between specular and diffuse echoes. Tilling et al. [16] defined specular echoes from CryoSat-2 as possessing PP values greater than 18, diffuse echoes as possessing PP values less than 9 and values in between for echoes of too much complexity. Other studies defined a threshold of specular echoes to possess PP values greater than 40 (e.g., [1,17]). Zakharova et al. [14] emphasises how the radar characteristics of AltiKa are 
different from the other missions and how their thresholds cannot be directly transferred to the processing of AltiKa data. Their study shows PP values of 30-90 around leads and lead edges, suggesting a threshold of PP values $>30$ to describe the specular returns. Lawrence et al. [38] state that, for AltiKa, waveforms with PP values higher than 18 are considered leads; those with values ranging from 5 to 18 are considered mixed; and PP values below 5 are used for sea ice. The threshold $(\mathrm{PP}<5)$ is applied in this study to identify reflections from sea ice and is further refined by only keeping MAX values within the interval 40-50 dB, following the results of Zakharova et al. [14].
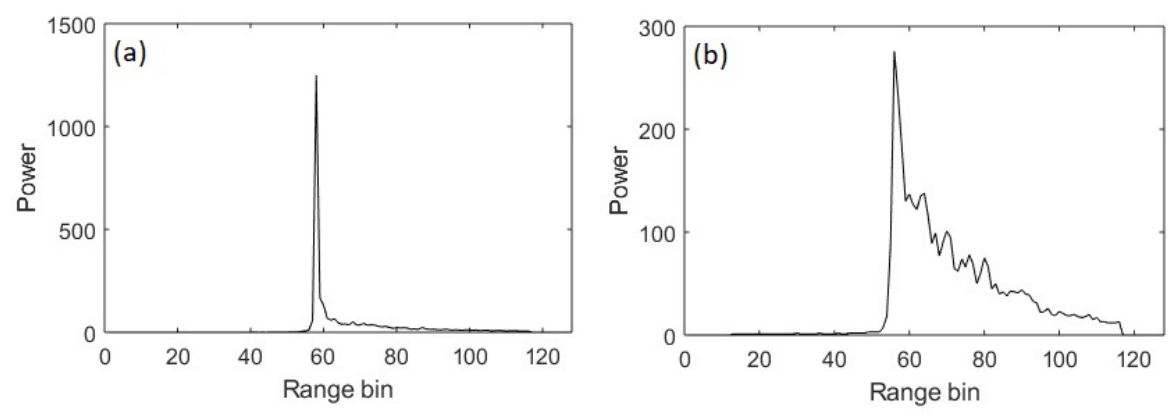

Figure 3. Example of AltiKa waveforms. (a) A specular return echo. (b) A diffuse return echo. We would like to emphasise the large difference in power return when you compare the specular and diffuse return echo.

While surface roughness is one of the factors that change the shape of the waveform, other factors also affect the radar signals behaviour in the snowpack. This in turn may be observed in the resulting waveform. A recent study by Stroeve et al. [39] based on a groundbased radar system, KuKa, deployed during the Multidisciplinary drifting Observatory for the Study of Arctic Climate (MOSAIC) showed that factors such as snow grain size and neighbouring grains, brine particles, the salinity of snow and the general scattering within the snowpack should be taken into account when it comes to interpreting the waveforms. However, for satellite-based systems, an assumption of a non-coherent sum of all scatterers is still usually accepted. The shape of the waveform is not dependent on surface roughness only, and the scattering in snowpacks also plays a role. We note that this is still an ongoing research topic, and it is still unclear exactly how these scatterers within the local snowpack propagate through the resulting radar signal from a larger surface (larger footprint) recorded by the satellite compared to a local surface observed by a ground-based system.

\subsection{Classification}

For classifying the MYI and FYI, we use four classifiers that have already been applied to Ku-band altimeter measurements $[15,17,27,28]$. The classifiers are trained separately for each year.

\subsubsection{Threshold-Based Classification}

We use here a simple threshold classification similar to Zygmuntowska et al. [15], as it makes no prior assumption on the distribution and is straightforward to implement. The goal is to estimate thresholds or intervals of the waveform parameters in order to discriminate between the sea ice types, as there should be a prominent difference due to the different surface characteristics of the sea ice types. The intervals will be determined by the most frequent measured value of each waveform parameter, i.e., the modal value \pm the standard deviation (std). There will be an interval for each sea ice type defined (i.e., FYI and MYI) by each waveform parameter over each year during 2014-2018. If a waveform possesses a parameter that falls within the overlapping part of the intervals (in both MYI and FYI), this measurement will be classified as ambiguous. If the parameters fall outside the determined thresholds, it will be labelled as no class. 


\subsubsection{Bayesian Classification}

The Bayesian classifier is based on Bayes' theorem (see Hanson et al. [40]), in which the classification problem is formulated in probabilistic terms. That is, based on the probabilities of each surface class and probabilities of each waveform parameter, a probability calculation is used to make the classification decision. Similar to Zygmuntowska et al. [15], the Gaussian kernel density estimates are used to model the parameter densities for each class. By using the Bayesian classification approach, the training dataset will be the same as the dataset used to estimate thresholds in the threshold-based classification scheme (this will be the case for all supervised classifiers). The Bayesian classifier will be tested on the entire data product available, where it will classify the pan-Arctic ice-covered region by using the ice type product from OSI SAF in order to describe the ice as either MYI or FYI.

\subsection{3. $k$-Nearest Neighbour (KNN) Classification}

A $k$-nearest neighbour $(\mathrm{KNN})$ classifier finds $k$ objectives in a provided training dataset that are closest to the test point; the class is based on a majority vote among these $k$ objects and the distance is based on the ordinary Euclidean metric; based on this distance, the classification output is determined $[17,28]$. The training data used are the same for all supervised classifiers (and threshold-based), and the features used are the waveform parameters (which particular parameters selected are described in Section 4).

\subsubsection{Random Forest (RF) Classification}

In addition to the threshold-based, Bayesian and KNN classifier, we also investigated the performance of a RF classifier, which has been applied to Ku-band CryoSat-2 data by Shen et al. [27] and demonstrated one of the highest classification performances compared to former studies. The RF classifier is a machine learning algorithm belonging to the category of decision tree classification algorithms. The RF classifier generates a large number of decision trees and, in each tree, the features are selected on a random basis. This allows the classifier to be robust with regards to noise $[27,28]$. The RF classifier is trained with the same training data as used in the previously mentioned classifiers (for each year) and is later applied to the entire pan-Arctic and compared with the OSI SAF reference data product for evaluation of performance. Classification trees numbering 150 were planted similar to Shen et al. [27] and Shu et al. [28].

\subsubsection{Classification Performance}

The classification performance will be calculated over the entire Arctic region (FYI/MYI dependent) for the selected period ( $\sim$ February, 35-day cycle). A correct classification for the different ice type classes is defined as the number of classified waveforms of each type by AltiKa, which are equivalent to the ice type from OSI SAF. Thus, FYI and MYI masks are applied to the classified data and the percentage of FYI and MYI (and ambiguous and no class for threshold-based) observations is calculated for each of the two areas. Therefore, the percentage of the waveforms that have been correctly classified is given as the following:

$$
\text { correct classification }=\frac{\text { \#class }_{\text {AltiKa }} \cap \text { \#class } \mathrm{OSI} \text { SAF }}{\text { \#class }_{\text {OSI SAF }}}
$$

which is similar to Zygmuntowska et al. [15].

Training performance is calculated in the Matlab Toolbox (used to train the classifiers) as 5-fold cross-validation by default. By using the Matlab Toolbox, an accuracy (validation) score is provided, which estimates a model's performance on new data compared to the training data and can be used to assist in choosing the model that performs the best. According to MATLAB's own definition, the score is the accuracy of all observations for cross-validation, counting each observation when it was in a held-out (validation) fold (see more on https://se.mathworks.com/help/stats/assess-classifier-performance.html, accessed on 18 April 2021). Such training performance accuracy scores are provided in 
Table 2. Here, it is mainly used as a figure to select which combination of waveform parameters is to be used for further classification.

Table 2. Overall training classification performance (\%) of three types of classifiers: Bayesian (Zygmuntowska et al. [15]), KNN (Rinne and Similä [17]) and RF (Shen et al. [27]) with four combinations of waveform parameters used as classification parameters, i.e., LEW, MAX and $\sigma_{0}$. The overall training performances of classification methods averaged over all four types of waveform/classification parameter combinations are $\mathrm{KNN}(81.70 \%)$, RF (83.76\%) and Bayesian (83.96\%). Combinationwise, the training performance is divided as: LEW $+\mathrm{MAX}+\sigma_{0}(82.97 \%)$, LEW $+\sigma_{0}(84.48 \%)$, LEW+MAX (83.35\%) and $\mathrm{MAX}+\sigma_{0}(80.10 \%)$. The highest average training performance (and smallest spread denoted by standard deviation, std) of each classifier (overall) is highlighted in bold. The lowest average classification performance (and largest spread) is highlighted with italics.

\begin{tabular}{ccccccccccccc}
\hline & \multicolumn{3}{c}{ LEW + MAX $+\sigma_{\mathbf{0}}$} & \multicolumn{4}{c}{ LEW $+\sigma_{\mathbf{0}}$} & \multicolumn{3}{c}{ LEW + MAX } & \multicolumn{3}{c}{ MAX $+\sigma_{\mathbf{0}}$} \\
\cline { 2 - 12 } Year & KNN & RF & Bayesian & KNN & RF & Bayesian & KNN & RF & Bayesian & KNN & RF & Bayesian \\
\hline 2014 & 85.88 & 86.35 & 85.51 & 86.32 & 86.86 & 86.35 & 85.95 & 87.20 & 86.25 & 78.65 & 80.11 & 83.44 \\
2015 & 94.44 & 94.50 & 94.06 & 94.57 & 95.42 & 94.54 & 94.50 & 94.57 & 94.50 & 92.09 & 92.47 & 94.27 \\
2016 & 80.58 & 81.36 & 79.97 & 78.88 & 82.57 & 79.93 & 79.86 & 80.75 & 79.97 & 68.75 & 73.93 & 76.88 \\
2017 & 77.53 & 80.37 & 80.10 & 77.56 & 84.42 & 79.59 & 76.95 & 80.34 & 79.66 & 72.34 & 75.93 & 79.69 \\
2018 & 78.24 & 80.00 & 80.68 & 78.34 & 80.25 & 81.69 & 77.53 & 80.51 & 81.63 & 75.19 & 77.36 & 80.41 \\
\hline Mean & $\mathbf{8 3 . 3 3}$ & 84.52 & 84.06 & 83.13 & $\mathbf{8 5 . 9 0}$ & $\mathbf{8 4 . 4 2}$ & 82.96 & 84.67 & $\mathbf{8 4 . 4 2}$ & 77.40 & 79.96 & 82.94 \\
Std & $\mathbf{7 . 0 2}$ & 6.14 & $\mathbf{6 . 0 4}$ & 7.30 & $\mathbf{5 . 8 5}$ & 6.27 & 7.37 & 6.24 & 6.23 & 8.98 & 7.35 & 6.75 \\
\hline
\end{tabular}

\section{Results}

\subsection{Waveform Parameters and Discrimination Suitability}

\subsubsection{Waveform Parameters Acquired over the Study Areas}

Following the pre-processing of AltiKa GDR as described in Section 3.2, we estimate the waveform parameters for FYI and MYI in February (35 day cycle) 2014-2018 for the study areas defined in Figure 2. It is evident from the box and whiskers plots (Figure 4) that the MAX and $\sigma_{0}$ show the largest differences in the distributions when comparing FYI and MYI alongside LEW. In 2015, PP also seems to be useful for distinguishing between the sea ice types. The estimated modal values of the waveform parameters with the associated variability $(s t d)$ are provided in Table 3.

Table 3. Statistical analysis of the waveform parameters: (MAX (maximum power), PP (pulse peakiness), $\sigma_{0}$ (backscatter coefficient), LEW (leading edge width) and TES (trailing edge slope)). The most frequent measured value (the modal value) for each date of FYI and MYI areas with the variability provided as one standard deviation. * LEW is shown without the scaling-factor of 0.01 .

\begin{tabular}{lcccccc}
\hline Cases & Year & MAX (dB) & PP $(\mathbf{d B})$ & $\sigma^{\mathbf{0}}(\mathbf{d B})$ & LEW $^{*}(\mathbf{m})$ & TES $^{\left(\mathbf{s}^{-1}\right)}$ \\
\hline FYI & 2014 & $48.91 \pm 1.26$ & $1.47 \pm 0.33$ & $7.70 \pm 1.26$ & $0.09 \pm 0.33$ & $-1.98 \times 10^{7} \pm 3.39 \times 10^{6}$ \\
FYI & 2015 & $49.50 \pm 1.16$ & $1.55 \pm 0.28$ & $7.76 \pm 1.16$ & $0.09 \pm 0.22$ & $-1.92 \times 10^{7} \pm 2.99 \times 10^{6}$ \\
FYI & 2016 & $47.55 \pm 1.33$ & $1.27 \pm 0.28$ & $6.18 \pm 1.33$ & $0.09 \pm 0.22$ & $-1.92 \times 10^{7} \pm 2.44 \times 10^{6}$ \\
FYI & 2017 & $48.91 \pm 1.32$ & $1.56 \pm 0.51$ & $7.43 \pm 1.32$ & $0.09 \pm 0.33$ & $-1.93 \times 10^{7} \pm 3.39 \times 10^{6}$ \\
FYI & 2018 & $48.91 \pm 1.18$ & $1.35 \pm 0.40$ & $7.93 \pm 1.18$ & $0.09 \pm 0.30$ & $-1.85 \times 10^{7} \pm 3.27 \times 10^{6}$ \\
MYI & 2014 & $47.00 \pm 1.15$ & $1.16 \pm 0.21$ & $5.01 \pm 1.16$ & $0.28 \pm 0.18$ & $-1.77 \times 10^{7} \pm 1.75 \times 10^{6}$ \\
MYI & 2015 & $45.78 \pm 1.24$ & $1.12 \pm 0.26$ & $3.85 \pm 1.24$ & $0.33 \pm 0.21$ & $-1.79 \times 10^{7} \pm 1.57 \times 10^{6}$ \\
MYI & 2016 & $46.00 \pm 1.39$ & $1.16 \pm 0.30$ & $4.31 \pm 1.39$ & $0.33 \pm 0.23$ & $-1.84 \times 10^{7} \pm 2.39 \times 10^{6}$ \\
MYI & 2017 & $47.01 \pm 1.49$ & $1.16 \pm 0.45$ & $4.87 \pm 1.49$ & $0.28 \pm 0.27$ & $-1.79 \times 10^{7} \pm 2.22 \times 10^{6}$ \\
MYI & 2018 & $47.01 \pm 1.49$ & $1.16 \pm 0.48$ & $5.20 \pm 1.50$ & $0.28 \pm 0.27$ & $-1.81 \times 10^{7} \pm 2.23 \times 10^{6}$ \\
\hline
\end{tabular}



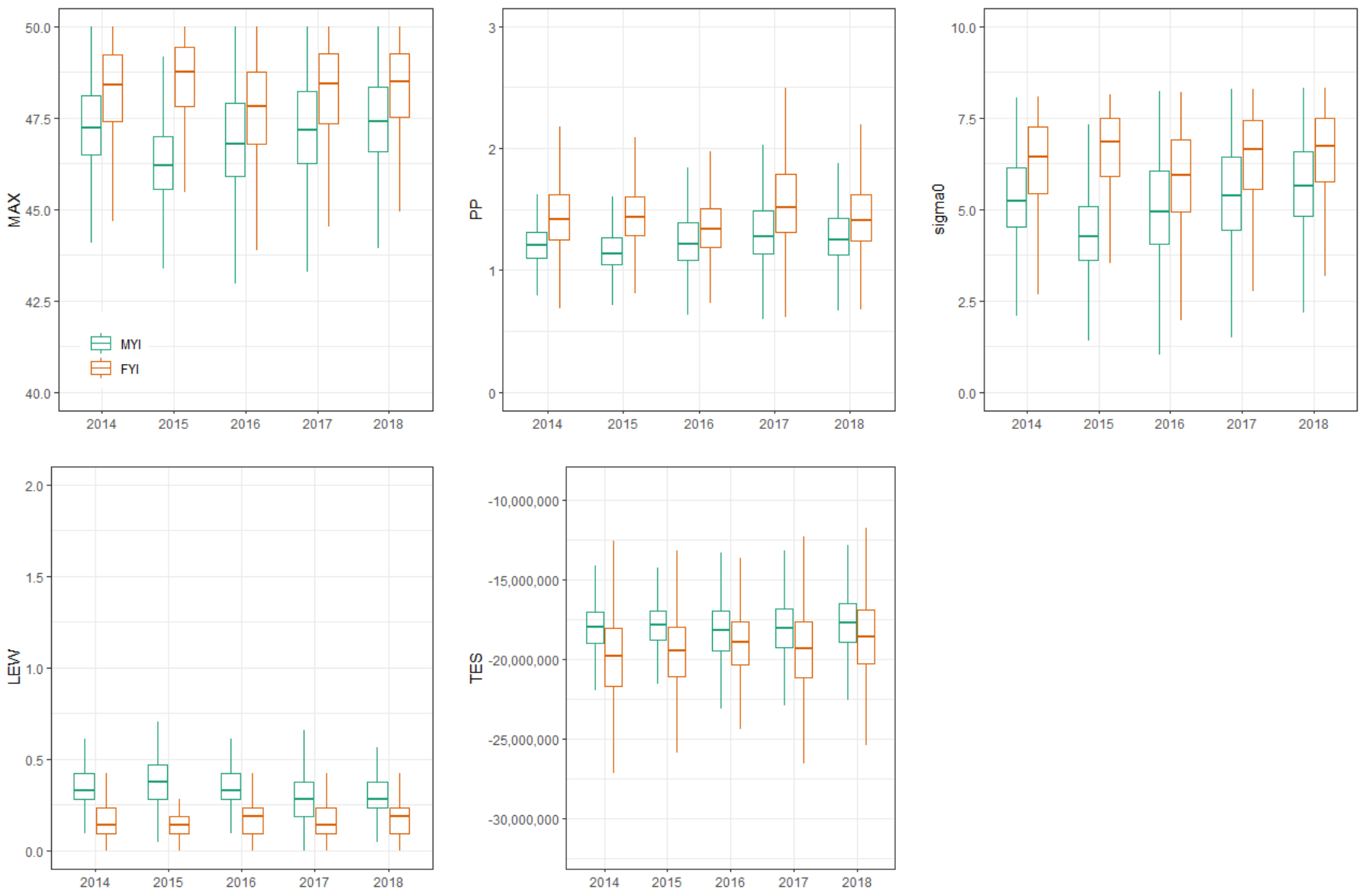

Figure 4. Box and whiskers plots of computed waveform parameters ( $M A X$ in $d B, P P$ in $d B, \sigma_{0}$ in $d B, L E W$ in metres and TES in $\mathrm{s}^{-1}$ ) in February 2014-2018 from the chosen study areas (Figure 2). PP, LEW and TES have user-defined limits applied to maintain the focus of the main distribution of the measurements rather than the outliers. Outliers have been removed to keep the plot simple.

Based on Table $3 \mathrm{MAX}, \sigma_{0}$ and PP are the parameters that overlap the least and show the largest variability between FYI and MYI. LEW is higher for MYI than FYI, which follows our expectation, but it is associated with the large variability (determined by standard deviation, $\sigma$ ), resulting in a large overlap between ice types. For TES, FYI has a higher decay rate when compared to MYI, which is expected due to an increase in quasi-specular returns in the observations over FYI, but once again the large variability allows for overlap between FYI and MYI. Thus, neither PP, LEW or TES seem suitable for a conventional threshold-based classification for AltiKa.

Prior studies of airborne Ku-band radar altimetry (e.g., Zygmuntowska et al. [15]) and CryoSat-2 (e.g., Rinne and Similä [17], Zygmuntowska [26]) have estimated PP, TEW and LEW to be the most suitable classifiers of sea ice types in the Arctic, with TEW and LEW describing, to some extent, the volume scattering of the reflected snow cover and the surface reflectance, respectively. In the sense of surface scattering, which is expected to be dominant for Ka-band radars, one would assume TEW (or TES in this study) and LEW to show similar behaviours over the respective ice types. While it is also true in this study, the variability allows for too much overlap between the intervals. The same applies to PP, suggesting MAX and $\sigma_{0}$ as the most suitable classifiers. This is in contradiction to the findings of Zygmuntowska [26]. They investigated CryoSat-2's waveform parameters and found a statistically significant difference between PP, SSD (stack standard deviation, a parameter stemming from delay doppler processing of SAR altimeters such as CryoSat-2), LEW and TEW. For MAX and $\sigma_{0}$, they found no distinct differences. They identified the SSD, LEW and PP as the best parameters to distinguish between FYI and MYI and stated 
that the MAX could not be confirmed as a reliable parameter for sea ice classification. The findings of Zygmuntowska [26] were also in contradiction with Zygmuntowska et al. [15], where they performed an analysis of airborne synthetic aperture Ku-band radar waveforms in order to classify sea ice types. Here they found TEW and MAX (Bayesian approach) or PP (threshold-based approach) to be the most suitable parameters. Thus, several studies have used different parameters based on their data and suitability requirements.

Inspired by these studies, we also investigated the parameters by cumulative probability functions (CDFs) (see Figure 5) and distances between FYI and MYI that were determined by Kolmogorov-Smirnov (KS) two-sided test similar to Zygmuntowska et al. [15] and Shu et al. [28] (see Table 4). These approaches result in the same overall behaviour, i.e., MYI has lower MAX, $\sigma_{0}$ and PP values when compared to FYI, reflecting that the surface of FYI is smoother than MYI. TES shows significantly more overlap and a smaller difference between the distributions, and LEW's CDFs are somewhat hard to analyse qualitatively as they do not follow a similar pattern as the rest of the parameters.

The result shows that the distributions for each class are significantly different at (at least) the 95\% level for each feature. It is observed that the differences between LEW, MAX and $\sigma_{0}$ are significantly larger than for PP and TEW. Surprisingly, LEW has the highest maximal distance $(0.60 \pm 0.12)$, suggesting this to be a valid classifier. However, as stated before, the classification intervals (see Table 3) overlap too much and, thus, LEW cannot be used in the threshold-based classification as it would include too many observations classified as ambiguous ice. TES and PP have lower maximal distances than LEW $(0.31 \pm 0.13$ and $0.37 \pm 0.12$, respectively), indicating the distributions to be similar for observations obtained over FYI and MYI and thus are not suitable as classifiers. Based on the maximal distances of MAX and $\sigma_{0}$ (both $0.45 \pm 0.10$ ), these show the largest potential to be the most suitable classifiers. The variability (std) also suggests that the distribution difference between MAX and $\sigma_{0}$ is more robust than the others, suggesting that LEW, TES and PP are more unreliable when describing a specific surface type. It could also indicate that the surface appearance can change a lot even though it is supposedly of the same type. Furthermore, we note that the maximal distance between the CDFs changes during the years (e.g., MAX is higher for 2014/2015 than 2016/2017), which indicates that the sea ice is different in the study areas for each year and that perhaps, for 2016-2017, the study areas are more similar in surface roughness than for other years. This is also why we base our training interval and data on data from each year and month and not only on one year because the sea ice is changing and is highly dynamic. This will likely also affect our performance results, since the ice used to train is essentially different each year (a more thorough discussion on the selection of suitable study areas is provided in Section 5.4). In summary, with our qualitative analysis based on distributions (Figures 4 and 5), intervals (Table 3) and maximal differences between the cumulative distributions by KS-test (Table 4), we propose MAX and $\sigma_{0}$ as the most suitable parameters for the classification of sea ice types by radar echoes from AltiKa using a threshold-based classifier.

Table 4. The actual maximal distance between the CDFs of MYI and FYI for each year from 2014 to 2018 was calculated by the Kolmogorov-Smirnov (two-sided) test for each waveform parameter.

\begin{tabular}{llllll}
\hline Year & MAX & PP & $\sigma_{0}$ & LEW & TES \\
\hline 2014 & 0.510 & 0.493 & 0.508 & 0.610 & 0.452 \\
2015 & 0.578 & 0.501 & 0.579 & 0.788 & 0.420 \\
2016 & 0.346 & 0.294 & 0.344 & 0.595 & 0.192 \\
2017 & 0.372 & 0.320 & 0.372 & 0.540 & 0.302 \\
2018 & 0.444 & 0.250 & 0.456 & 0.479 & 0.172 \\
\hline Mean & 0.450 & 0.372 & 0.452 & 0.602 & 0.308 \\
Std & 0.096 & 0.117 & 0.096 & 0.116 & 0.128 \\
\hline
\end{tabular}



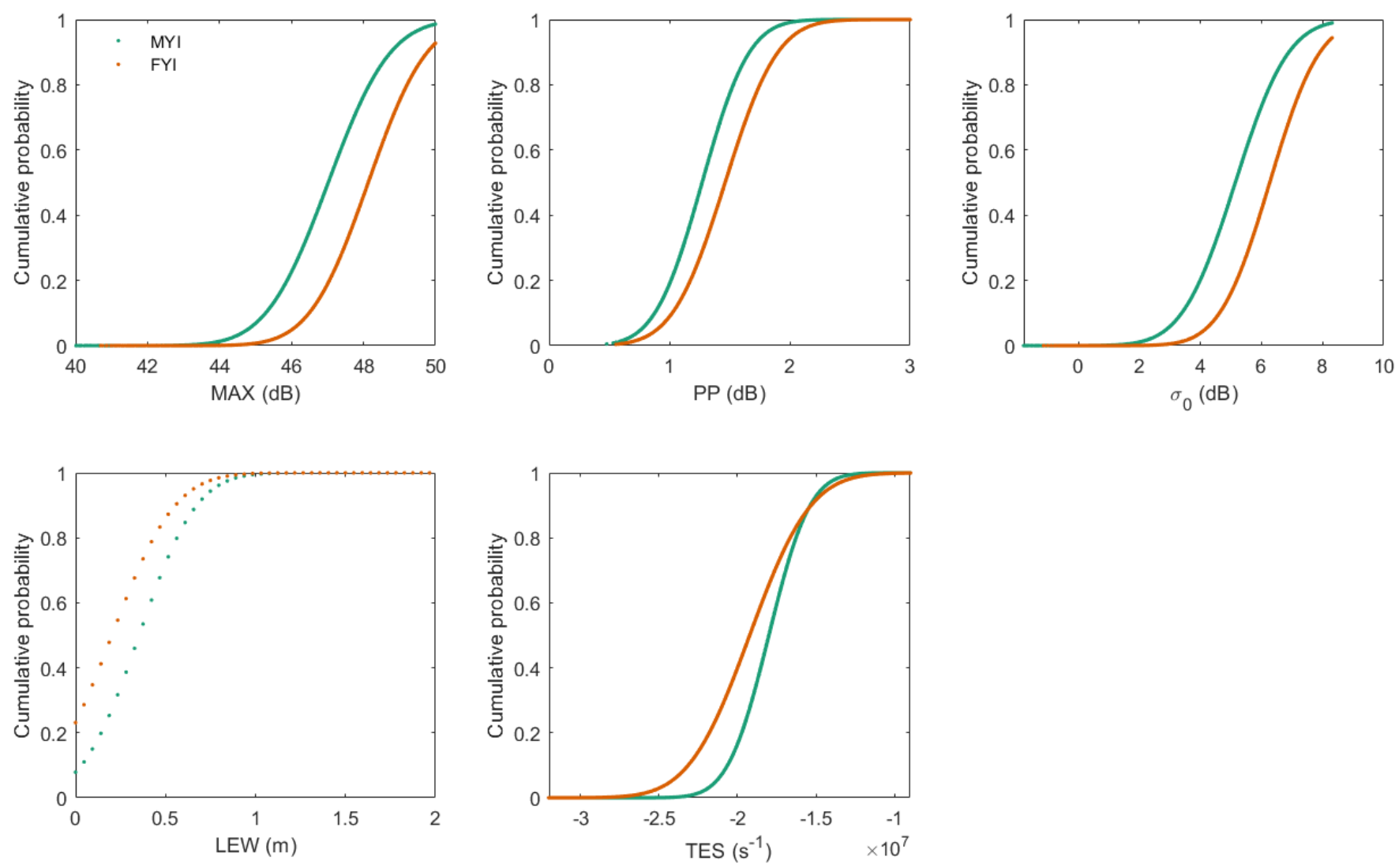

Figure 5. The cumulative probability distributions (CDFs) for the five different AltiKa waveform parameters for all years (2014-2018) combined are shown by MYI and FYI in green and brown, respectively. LEW, PP and TES use the same limits as in Figure 4.

\subsubsection{Pan-Arctic Distribution of the Waveform Parameters}

The spatial pan-Arctic distributions of MAX, $\sigma_{0}$ and LEW from 70 to $81.6^{\circ} \mathrm{N}$ for February (35 day cycle) 2014-2018 are shown in Figure 6. Comparing with the distribution of OSI SAF sea ice type (contour lines in Figure 6), both MAX and $\sigma_{0}$ are promising when used as classifier.

MAX (Figure 6, left column) shows relatively low values associated with MYI north of the Canadian Archipelago, which is as expected. Most FYI and open ocean have MAX values $>48 \mathrm{~dB}$ and are difficult to separate by using MAX alone. The largest drawback when using MAX is the large amount of MYI observed in the Beaufort Sea (in OSI SAF data in 2014 and 2015), which is misclassified as FYI when using the MYI intervals from Table 3. Furthermore, MAX does not show ice with values lower than $\sim 44 \mathrm{~dB}$, even though Zakharova et al. [14] estimated rough sea ice to range from 40 to $50 \mathrm{~dB}$. Since AltiKa does not cover the entire MYI area due to its polar gap, it is not possible to investigate whether it also applies to areas where the rougher, older and more deformed sea ice occurs, e.g., north of Greenland. The distribution of $\sigma_{0}$ (Figure 6, centre column) suggests that it is also a promising classifier for discriminating between MYI and FYI when compared to OSI SAF sea ice types. However, in some years (2014 and 2015), it appears to recognise MYI near the Barents Sea and Kara Sea which is not consistent with OSI SAF. This suggests a combination of MAX and $\sigma_{0}$ to be the most suitable method for discriminating between sea ice types in the Arctic using AltiKa data. 
MAX
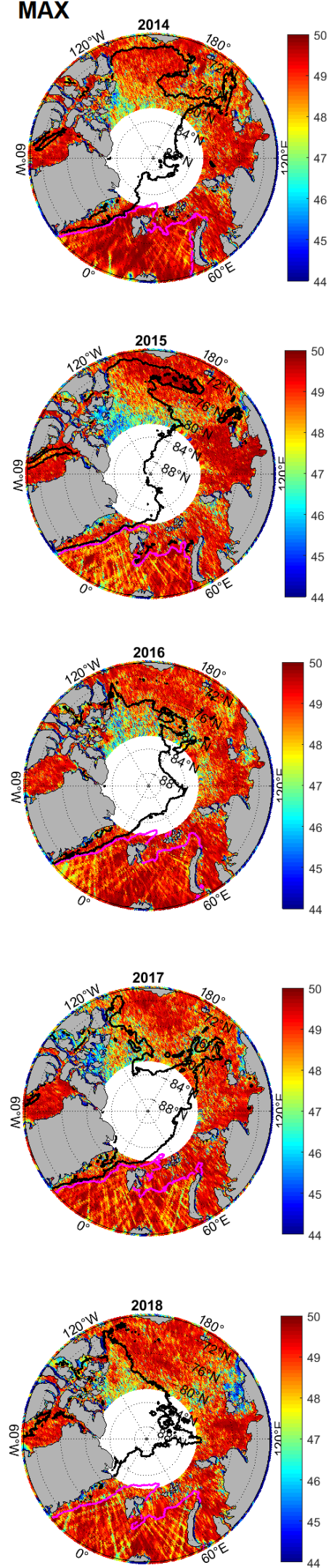

\section{Backscatter}
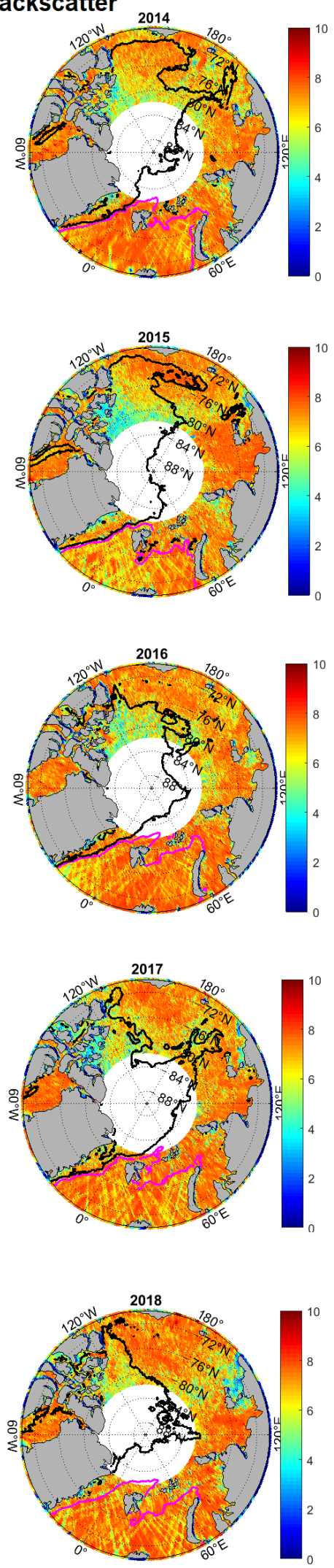

LEW
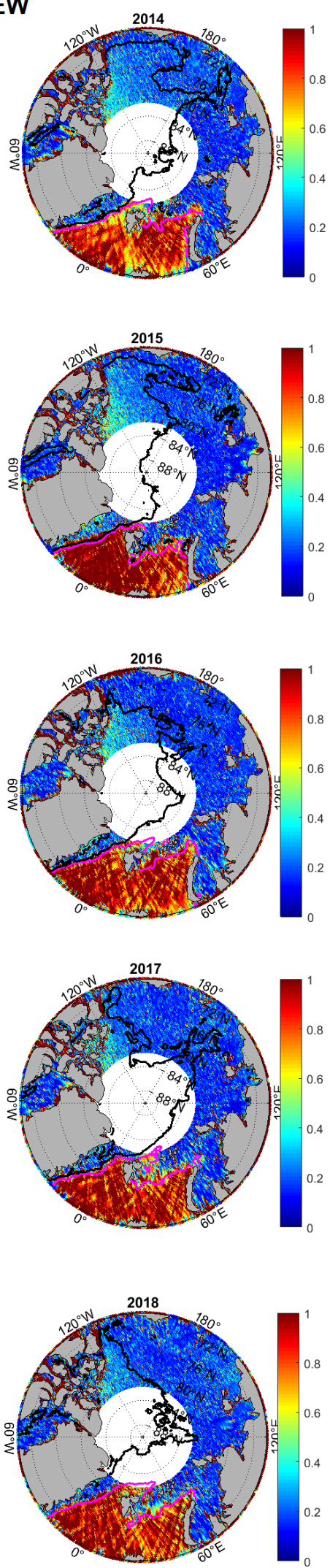

Figure 6. Spatial distribution of MAX (limits 44-50 dB), $\sigma_{0}$ /backscatter (limits 0-10 dB) and LEW (limits 0-1 m) over the Arctic from 70 to $81.6^{\circ} \mathrm{N}$ for a 35 day cycle ( February) in 2014-2018 interpolated to the OSI SAF $10 \mathrm{~km}$ grid with a polar stereographic projection. The black line denotes MYI/FYI ice edge and the magenta line denotes ice/ocean edge. 
Based on the KS-test, the suitable parameters for discriminating between FYI and MYI using our test areas are LEW (with the largest difference between MYI and FYI CDF's), MAX and $\sigma_{0}$. Thus, we have also investigated the pan-Arctic distribution of LEW (see Figure 6 (right column)). It is clear from Figure 6 (right column) why there is such a big overlap in the intervals determined by the threshold for FYI and MYI. While there are high LEW values associated with MYI north of the Canadian Archipelago, the high values do not spatially cover the whole MYI area as defined by OSI SAF. Furthermore, over the entire FYI area, there is a large amount of high LEW values, which potentially stem from heavily deformed FYI. However, a striking feature in the pan-Arctic distribution of LEW is the clear difference between sea ice (FYI and MYI shown in blue colours) and open ocean (shown in red colours). This suggests that for AltiKa, LEW can be used to discriminate sea ice (with values of $0.0-0.5 \mathrm{~m}$ ) from the open ocean (with values above $\sim 0.6 \mathrm{~m}$ ). By comparing this open ocean/sea-ice edge visually with OSI SAF's sea ice edge (see magenta contour lines in Figure 6), there seems to be a good agreement. We encourage further studies in using the Ka-band (such as AltiKa) waveform parameters in order to distinguish open ocean from sea ice to support the sea ice edge mask that is applied when estimating sea ice thickness products. The sea ice edge mask is usually provided by complementary measurements such as the OSI SAF sea ice edge product, and it could be useful to investigate the question of whether the altimetric measurements can provide an additional reference data set to improve the sea ice edge masks.

We further investigate the question of which combination of MAX, $\sigma_{0}$ and LEW, for each year, will present the highest training performance with the lowest spread by using three supervised classifiers (i.e., KNN, RF and Bayesian). In order to investigate the overall accuracy of the models, we use data from the FYI/MYI study areas (defined in Figure 2) as a training dataset and four combinations of waveform parameters, i.e., $\mathrm{LEW}+\mathrm{MAX}+\sigma_{0}$, $\mathrm{LEW}+\sigma_{0}, \mathrm{LEW}+\mathrm{MAX}$ and $\mathrm{MAX}+\sigma_{0}$.

The overall highest training performance (averaged over all five years) is achieved by using RF $(85.90 \%)$ and a combination of LEW $+\sigma_{0}$ as classifiers. Using KNN, the highest overall training performance $(83.33 \%)$ is achieved by using a combination of $\mathrm{LEW}+\mathrm{MAX}+\sigma_{0}$. The Bayesian classifier achieves the highest overall training performance $(84.42 \%)$ by using both a combination of LEW $+\sigma_{0}$ and LEW + MAX. When averaging the performance over five years for each combination, the combination of $\mathrm{LEW}+\sigma_{0}$ had the highest training performance with an average of $84.48 \%$ and the Bayesian approach proves best with an overall training performance of $83.96 \%$. It is noteworthy to observe that the combinations of $\mathrm{MAX}+\sigma_{0}$, which according to the threshold-based classification scheme were superior to any classification based on single parameters (Table A1), possess the overall lowest training performance $(80.10 \%)$ when using the supervised classifiers. Furthermore, it had the largest spread (denoted by standard deviation) for all years as well. Based on the statistics of the training classification performance, we further investigate the supervised classification of sea ice types based on a combination of $\mathrm{LEW}+\sigma_{0}$, since the overall training performance showed this combination as the best and the training performances of RF and Bayesian (based on the five years with $85.90 \%$ and $84.42 \%$, respectively) are the highest here as well. One of the classifiers (RF) for LEW $+\sigma_{0}$ also had the smallest spread of $5.85 \%$. For KNN, it had the second smallest spread (of $7.30 \%$ ) and the second-largest spread for Bayesian (of 6.27\%) (see Table 2).

\subsection{Classification of Sea Ice Types in the Arctic by Four Classifiers}

In this section, we aim to classify the pan-Arctic sea ice types (FYI and MYI) by using four classifiers (KNN, RF, Bayesian and threshold-based) and to test their performance following the method described in Section 3.3.5.

As described in Section 3.3.1, the threshold-based classification partitions the AltiKa data into four classes, i.e., FYI, MYI, ambiguous and no class, where the FYI and MYI classes are determined by the intervals provided in Table 3 . When combining MAX $+\sigma_{0}$ in the threshold-based classification, only values within the same ice type interval (e.g., MYI in 
both MAX and $\sigma_{0}$ ) will be considered as MYI and the case is similar for FYI, otherwise they will be considered as ambiguous. Based on the statistics presented in Appendix A, the combined classification MAX $+\sigma_{0}$ shows the highest overall performance, where the single parameter classifications using $\sigma_{0}$ performs best over MYI and MAX over FYI. Hence, for the threshold-based classification, the combination of MAX $+\sigma_{0}$ is used. Based on the outcome of Section 4.1.2, we use a combination of LEW $+\sigma_{0}$ in the case of all three supervised classifiers (KNN, RF and Bayesian).

In order to investigate the classification performance, the classified AltiKa data are compared with reference data from OSI SAF. By interpolating the classified AltiKa data into the grid of the reference data, it is possible to determine the classification rate. The classified AltiKa data are interpolated into the grid points of OSI SAF that are defined as sea ice. Thus, the classification of AltiKa is constrained by the ice edge data from OSI $\mathrm{SAF}$, which determines the border between ice and ocean. The reference data possess the following four types—ocean, FYI, MYI and ambiguous — and the data are provided in a polar stereographic $10 \mathrm{~km}$ grid for each day in February, which has been averaged to provide a monthly estimate, see Figure 7 and Section 2. Open water is defined as having ice coverage of less than $30 \%$, while FYI and MYI both have an ice concentration above $30 \%$.

The classification performances of the supervised classification with waveform parameters LEW $+\sigma_{0}$ and for threshold-based classification with parameters $\mathrm{MAX}+\sigma_{0}$ are provided in Table 5 and shown in Figure 7. In terms of overall performance and considering only the supervised classifiers, KNN has the lowest FYI (91.27\%), but highest MYI (34.07\%), and the Bayesian is the highest for FYI (92.82\%) and the lowest for MYI (27.03\%). RF ranges between the values of KNN and Bayesian, with overall performances closer to the Bayesian for FYI (91.85\%) and to KNN for MYI (33.24\%); however, RF has the overall lowest spread for both FYI and MYI. For FYI, the Bayesian approach performs the best in all years except 2015. In 2015, RF showed the highest classification accuracy for FYI with $93.87 \%(0.02 \%$ better than the second-highest classifier for FYI in 2018 that is KNN). Overall, RF classifies FYI with high confidence ranging from 90.02 to $93.91 \%$, while also keeping a relatively high classification performance of MYI (24.95-39.42\%) compared to, e.g., the Bayesian approach, which shows the worst-case classification performance of MYI in 2014 to be less than $20 \%$. The threshold-based classifier is low in performance of FYI $(56.56-68.67 \%)$ and, in comparing with statistics and figures in Appendix A, it is clear that this is caused by either ambiguous ice (due to overlapping intervals) or by misclassification (FYI as MYI or vice versa). The threshold-based classification, however, achieves higher results in all years for MYI compared with the supervised classifiers and achieves an overall classification performance of $39.30 \%$. However, this is still a low classification performance compared to former Ku-band studies (e.g., $[15,27,28])$.

While all three supervised classifiers improves significantly for FYI compared to the threshold-based approach, all classification methods show relatively poor performance over MYI. Even the best classifier over MYI, i.e., the threshold-based, has low performance, which can be caused by the increased numbers in measurements classified as ambiguous introduced by using the combination of $\mathrm{MAX}+\sigma_{0}$ to some extent. This class of ambiguous measurements is not included in either of the three supervised classifiers, i.e., the only classification results that can occur here are FYI or MYI. The low classification accuracy of MYI by the supervised classifiers is somewhat surprising, as KNN, Bayesian and RF are generally viewed as more sophisticated (and often better) classifiers than the threshold approach. This is most likely caused by the limitations of the training dataset, which only covers a part of the MYI cover north of Canada and does not include the MYI of other areas of the Arctic Ocean, which may represent different characteristics of MYI than observed here. When comparing the spatial distribution of the sea ice types classified by KNN, RF and Bayesian (Figure 7), it follows a similar pattern as for the threshold-based classifier. An increased amount of misclassified MYI is evident north of the East Siberian Sea (average misclassification of FYI as MYI ranges from 4.39 to $12.14 \%$ for the three classifiers). We expect this to be caused by highly deformed FYI (driven by winds and ocean currents), 
allowing the surface to appear rougher and to behave similar to MYI (see also Section 5). It may be that the assumption of FYI and MYI being relatively easy to discriminate due to significant differences in surface characteristics does not apply when using Ka-band, and/or the mixed sea ice types dominates the surface signatures of the waveform.

Furthermore, the penetration capabilities of Ku-band into the snow cover (as the radar echo is a function of both surface characteristics and volume scattering within the snow layer) could potentially provide a necessary source of information to discriminate between sea ice types, since MYI usually has a thicker snow cover compared with FYI. This information is not necessarily achieved when using Ka-band as it has less penetration [38]. The volume scattering occurring when the radar pulse penetrates the snow cover can at times be observed in the widening of LEW and TEW (often related to MYI sea ice types); thus, these parameters carry crucial information that is not utilised in the Ka-band classification [15]. Prior studies using Ku-band radar altimetry (e.g., $[15,17,27])$ all used a combination of either LEW or TEW/TES, which could have improved their classification for MYI. The penetration capabilities of Ka-band in relation to snow and the importance of drift are discussed further in Section 5.2. Lastly, it should be noted that the classification performance of the supervised classifiers was expected to improve, especially for FYI, since these approaches include only the classification of FYI and MYI, excluding the classes of ambiguous ice and no class. As most of the Arctic Ocean south of $81.6^{\circ} \mathrm{N}$ is covered by FYI and includes values of MYI that might appear to be smoother than deformed MYI (see the spatial distribution of MAX, $\sigma_{0}$ and LEW in Figure 6), this also affects the results compared to the classification by thresholds that includes two additional classes. However, this study demonstrates how rough ice is particularly easy to recognise in the retrieved surface classifacation by using Ka-band alone (the main MYI cover shown in Figure 7). Based on this, we highlight the potential of an increased performance in ice type classification by combining Ka-band and Ku-band altimetry as an add-on to the more obvious retrieval of snow depth, and we encourage this approach to be investigated further.

Table 5. Classification performance (\%) of four different types of classifiers: KNN (Rinne and Similä [17]), RF (Shen et al. [27]), Bayesian (Zygmuntowska et al. [15]) and thresholdbased. Each supervised classifier has used LEW $+\sigma_{0}$ as classifying parameters and threshold-based has used MAX $+\sigma_{0}$. Bold denotes the highest overall (averaged) classification performance and smallest spread (variability by $s t d$ ) for FYI and MYI. * Only classification performance correctly classified as MYI in MYI area and FYI in FYI area is shown here. The reader is referred to Appendix A for more statistics on the threshold-based classification.

\begin{tabular}{lcccccccc}
\hline & \multicolumn{2}{c}{ KNN } & \multicolumn{2}{c}{ RF } & \multicolumn{2}{c}{ Bayesian } & \multicolumn{2}{c}{ Threshold * } \\
\cline { 2 - 9 } Year & FYI & MYI & FYI & MYI & FYI & MYI & FYI & MYI \\
\hline 2014 & 93.38 & 26.76 & 93.91 & 24.95 & 95.61 & 17.47 & 60.31 & 37.59 \\
2015 & 93.85 & 30.13 & 93.87 & 31.46 & 89.79 & 34.14 & 68.41 & 33.74 \\
2016 & 91.40 & 36.90 & 91.17 & 33.73 & 91.49 & 24.10 & 68.67 & 41.74 \\
2017 & 87.86 & 42.99 & 90.02 & 39.42 & 90.65 & 33.83 & 67.90 & 40.93 \\
2018 & 89.84 & 38.08 & 90.27 & 36.64 & 92.81 & 25.62 & 56.56 & 50.70 \\
\hline Mean & 91.27 & 34.07 & 91.85 & 33.24 & $\mathbf{9 2 . 8 2}$ & 27.03 & 65.23 & $\mathbf{3 9 . 3 0}$ \\
Std & 2.49 & 6.49 & $\mathbf{1 . 9 1}$ & $\mathbf{5 . 5 2}$ & 2.27 & 7.05 & 5.58 & 6.60 \\
\hline
\end{tabular}



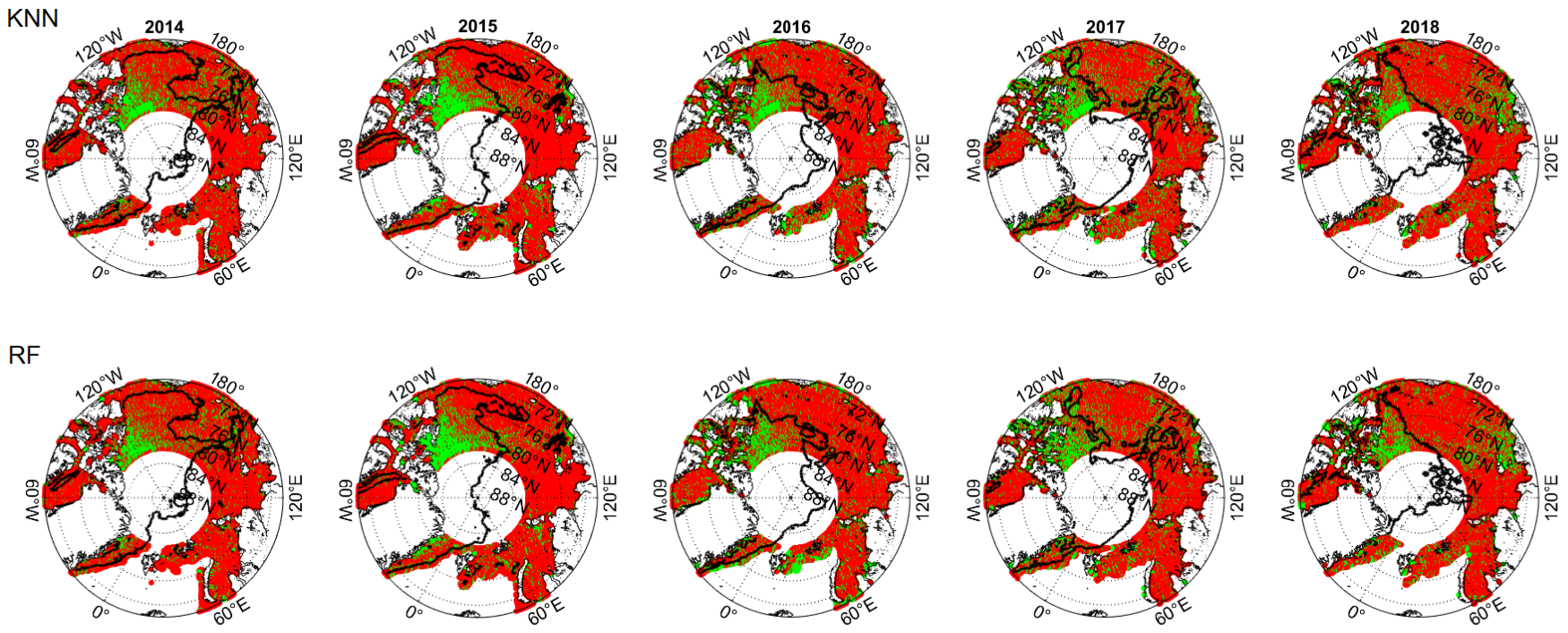

Bayesian
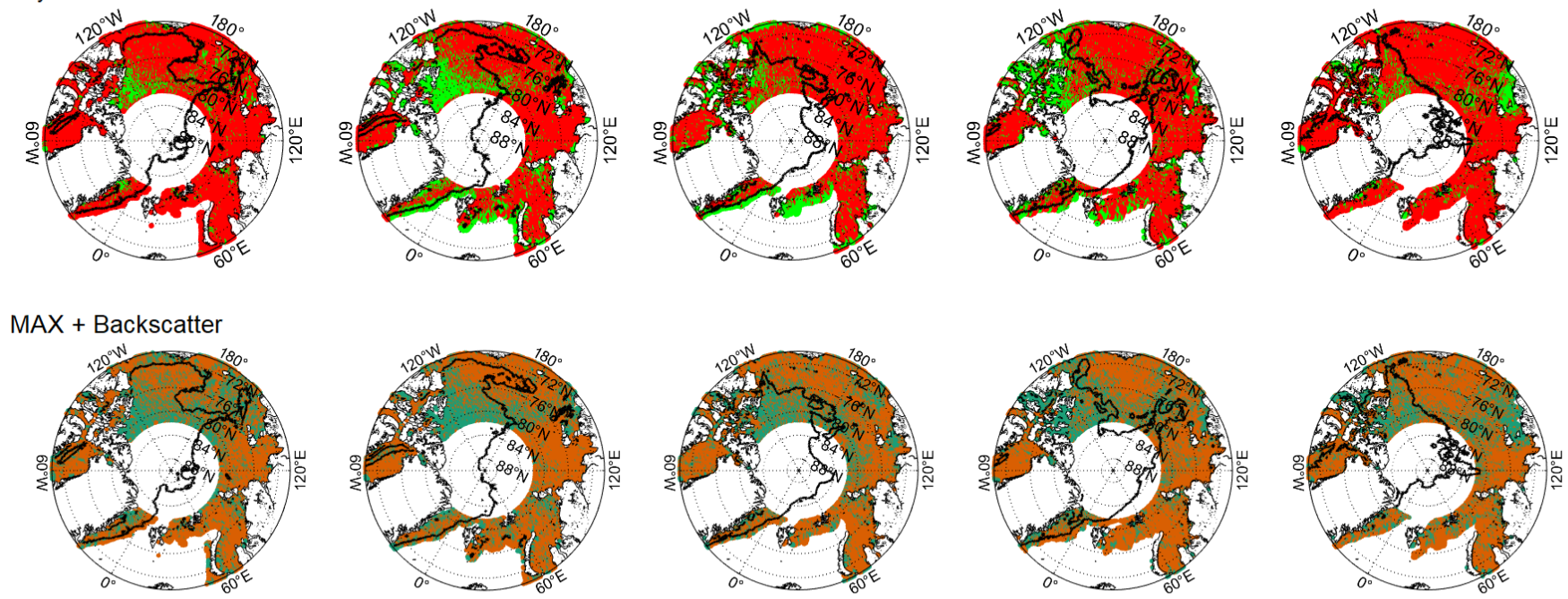

OSI SAF
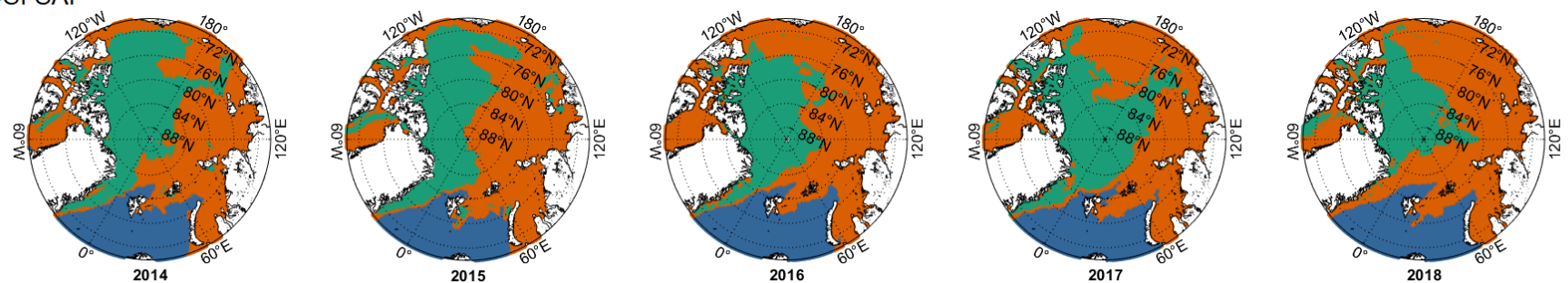

Figure 7. Classification of sea ice types by AltiKa radar echo waveforms in February (35 day cycle) 2014-2018, with $\mathrm{KNN}, \mathrm{RF}$ and Bayesian classifiers (supervised classifiers), using a combination of waveform parameters LEW $+\sigma_{0}$ and a threshold-based classifier using waveform parameters MAX $+\sigma_{0}$. For the supervised classifiers, FYI is denoted by bright red and MYI by bright green. For the threshold-based classifier, FYI is denoted by brown and MYI by green. For reference, OSI SAF sea ice type is presented with FYI denoted by brown, MYI by green and open ocean by blue. Black contour lines denote the MYI/FYI edge provided by OSI SAF. 


\section{Discussion}

\subsection{Comparison with Prior Studies}

The classification of sea ice types by $\mathrm{Ku}$-band radar echoes (waveforms) has been researched during the last decade (e.g., [15,17,26-28]). Zygmuntowska et al. [15] showed some of the first classification results of sea ice types by using measurements from the Airborne Synthetic Aperture and Interferometric Radar Altimeter System (ASIRAS). Here, they investigated the classification of several sea ice regimes (new ice, FYI and MYI) with a threshold-based and a Bayesian approach. For Zygmuntowska et al. [15], the thresholdbased classification performance for FYI reached $72.6 \%$ and it reached $68.6 \%$ for MYI. The overall performance was $72.4 \%$ (with PP as the only classifying parameter). Data used for validation by Zygmuntowska et al. [15] were a mixture of Advanced SAR (ASAR), in situ photo camera and electromagnetic (EM) observations, where these observations were utilised to estimate the surface types the airborne altimeter measurements encountered. The Bayesian approach showed slightly better results with a classification performance of $78.7 \%$ (FYI) and 81.7\% (MYI) and an overall performance of 80.3\% (using TEW and MAX as parameters). With an overall performance being only $\sim 8 \%$ better when using the Bayesian approach than the threshold-based approach, we used both in this study.

Sea ice classification with space-borne altimeters has primarily been investigated by using Ku-band CryoSat-2 measurements (e.g., [17,27,28]). Rinne and Similä [17] classified CryoSat-2 radar altimeter echoes by the use of $k$-nearest neighbour (KNN) in the Kara Sea to support operational navigation, and they achieved classification rates in March 2014 of FYI $(<70 \mathrm{~cm})$ at $15-26 \%,(>70 \mathrm{~cm})$ at $75-92 \%$ and MYI at 77-92\%. Shen et al. [27] applied a random forest (RF) machine learning approach for determining sea ice types in the Arctic. They planted 150 classification trees (by RF) using six (PP, MAX, SSD, LEW, TEW and $\sigma_{0}$ ) waveform parameters. The classification performances were $82.58 \%$ for FYI and $72.53 \%$ for MYI. Finally, Shu et al. [28] used an object-based RF (ORF) approach as a classifier, which combines a boosting sampling strategy and classification and regression trees. They achieved an overall classification performance of $92.7 \pm 3.3 \%$ (FYI) and $83.8 \pm 3.59 \%$ (MYI). As for Rinne and Similä [17], Shu et al. [28] and Shen et al. [27], all studies were validated against the Antarctic Research Institute (AARI) sea ice charts. Shu et al. [28] further applied the aforementioned methods (RF, Bayesian and KNN) to their CryoSat-2 segmented data to perform a direct comparison with classification performance. The overall performance of the analysis conducted by Shu et al. [28] is shown in Table 6 (directly adapted).

Table 6. Summary (from Shu et al. [28]) of overall classification performance (\%) with variability (standard deviation, std) from four prior studies on Ku-band radar altimeters (Shu (object-based random forest/ORF), Shen (random forest/RF) and Rinne ( $k$-nearest neighbour/KNN) on CryoSat-2; Zygmuntowska (Bayesian) on Airborne Synthetic Aperture and Interferometric Radar Altimeter System (ASIRAS)). The summary is based on the classification of sea ice during the period of November 2015-May 2016.

\begin{tabular}{lcccc}
\hline & Shu (ORF) & Shen (RF) & Zygmuntowska (Bayesian) & Rinne (KNN) \\
\hline FYI & $92.7 \pm 3.3$ & $82.9 \pm 9.48$ & $73.6 \pm 13.3$ & $90.0 \pm 10.9$ \\
MYI & $83.8 \pm 3.59$ & $72.5 \pm 2.95$ & $87.5 \pm 1.5$ & $64.4 \pm 10.5$ \\
\hline
\end{tabular}

When comparing overall performance, ORF provides a better classification of FYI compared to all the other methods. The Bayesian approach has the overall highest classification performance for MYI. Ignoring the ORF classifier and, thus, using only RF, KNN and Bayesian, an opposite pattern was observed for Ka-band observations in this study (Table 5). Here, KNN had the highest overall classification performance (of supervised classifiers) for MYI (34.07 $\pm 6.49 \%)$, and the Bayesian had the highest for FYI (92.82 $\pm 2.27 \%)$. In comparison, RF for Ka-band demonstrated to be in the middle in terms of overall performance for both FYI and MYI but also had the smallest spread (standard deviation). However, what is most remarkable is the fact that while this study only investigated $\mathrm{KN}$, 
RF and Bayesian and not the ORF-classifier that outperforms all classifiers for FYI (and two-thirds for MYI classification according to Shu et al. [28]), the Bayesian classifier (in this study) outperforms the ORF for FYI-actually, all the classifiers were outperformed by the same classifiers in the Ka-band for FYI. However, the same does not stand for the classification performance of MYI. Thus, while the near-surface characteristics that Ka-band was able to retrieve due to low penetration allowed for the easy identification of FYI, it was unable to capture the less rough MYI. Thus, studies in combining Ku-band and Ka-band are encouraged since not only does it appear to possess great potential in estimating sea ice types from the radar echoes but also a possibility in discriminating between rough and smooth MYI when combining Ka-observations and Ku-observations.

\subsection{Snow Cover and Drift Speed Influence}

The radar signal waveform is dependent on the properties of sea ice and snow [21]. Snow properties influencing the signal are snow depth and snow density, and atmospheric temperatures can influence snow, causing it to either change the speed of penetration or the appearance of the scattering surface [26]. Both effects caused by atmospheric temperatures have been found to influence the shape of the radar signal and the scattering surface [41]. Sea ice itself does not experience volume scattering and, thus, surface roughness is the main influence on the reflected radar waveform [21]. Generally MYI carries a larger snow load than FYI (MYI has approximately double the snow depth of FYI), which with penetration into the snowpack would be reflected in the radar echoes, e.g., by the waveform parameter TES/TEW [42]. Several studies (e.g., [26,28,43]) highlight the importance of estimation of snow depth for the Ku-band (mostly based on CryoSat-2 measurements), since the $\mathrm{Ku}$-band is often expected to penetrate the snow cover until the snow/ice interface. If this is not the case (e.g., due to wet snow cover or refreezing), wet snow significantly changes the appearance of the resulting signal and cannot be neglected, as it will cause a bias in the freeboard estimation and, subsequently, the ice thickness $[15,28,43,44]$. The Ka-band has less penetration into the snowpack, which was confirmed by the studies of Guerreiro et al. [43] showing that the maximum penetration depth for Ka-band is smaller than $5 \mathrm{~cm}$ for snow grains larger than $2 \mathrm{~mm}$. Thus, the amount of volume scattering measured by the Ka-band is only from a very thin subsurface layer [45]. This could explain how TES does not appear to show a great difference between FYI and MYI simply because the Ka-band does not allow for the same penetration as Ku-band and, thus, does not result in a significant difference in the reflected radar echo.

Misclassification of sea ice types can be caused by changes in the typical ice typedependent surface characteristics, e.g., by deformation [26] and/or melting and refreezing. As we study the sea ice classifications from February, melting and re-freezing should not affect our results significantly. However, deformation caused by the drift of sea ice driven by wind and ocean currents can affect our results to a certain extent. In order to properly understand the surface roughness and its dependency on the ice type classification (Figure 7), we have inspected sea ice drift maps in the month prior to the classification (January) downloaded from the NASA Distributed Active Archive Center (DAAC) at the National Snow and Ice Data Centre (NSIDC), as shown in Figure 8. When we investigated the sea ice drift maps from January 2016 and compared it to the other years (2014-2015; 2017-2018), a change in the drift pattern in the Arctic Ocean was observed, which allowed us to assume that the FYI in that year has become more deformed than the other years, causing it to appear more similar to MYI resulting in misclassification. This indicates that the characteristics of AltiKa are dependent on the surface type in the sense of flat and deformed ice, similar to findings in Zygmuntowska [26]. Thus, we can likewise conclude that as long as the surface properties (flat or deformed) follows the expected sea ice types (FYI or MYI), a classification of these two sea ice types is possible. The drift and the aforementioned conclusion also explains the missing MYI classification near the Beaufort Sea, simply suggesting that the MYI in this area has a smoother surface. This also explains 
the overestimation of MYI near the Siberian Sea in both 2017 and 2018-in reality, these areas were covered by heavily deformed FYI.
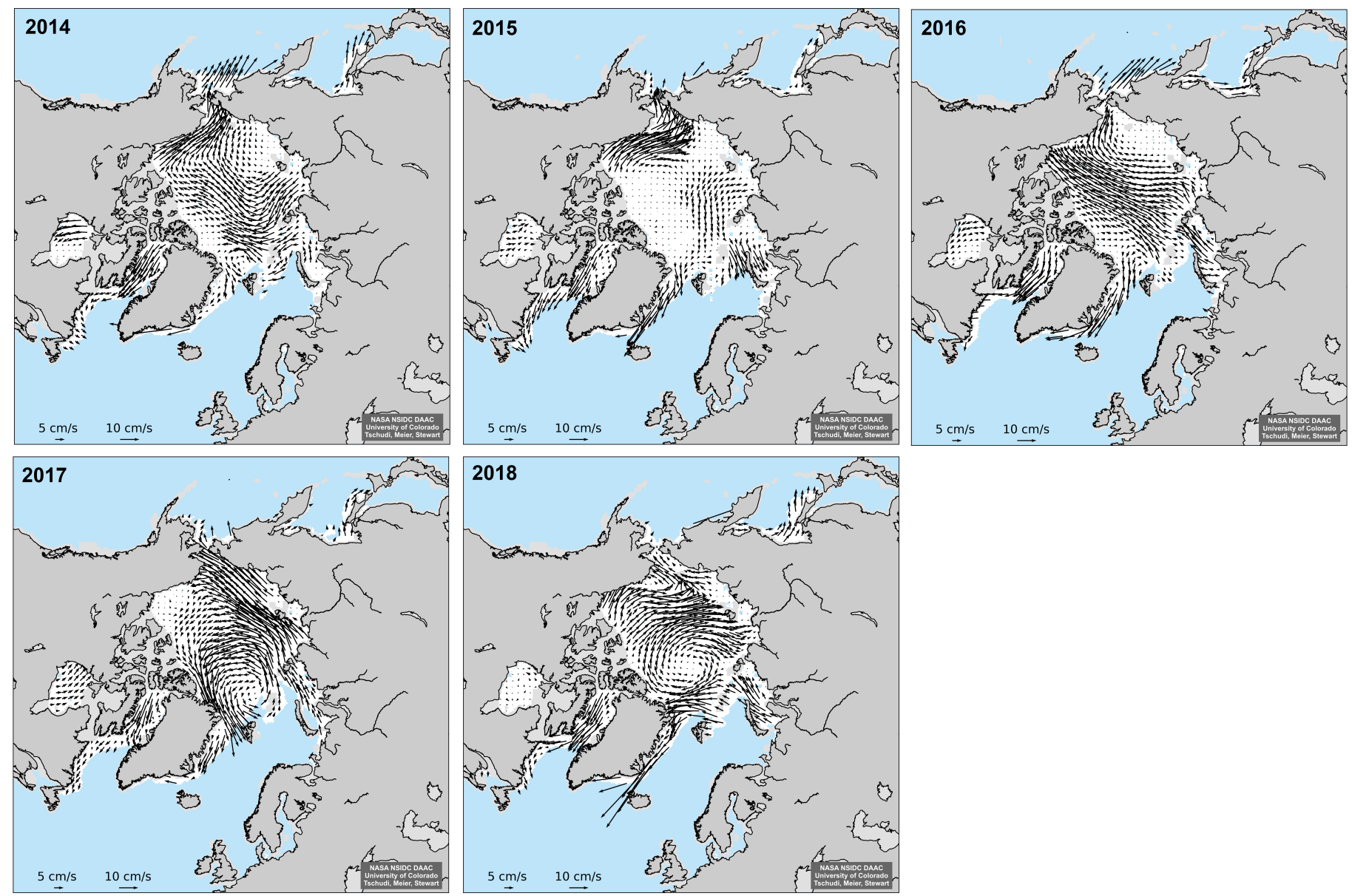

Figure 8. Weekly drift patterns of the Arctic acquired from 15 to 21 January (in the years 2014-2018). Available from https:/ / daacdata.apps.nsidc.org/pub/DATASETS/nsidc0116_icemotion_vectors_v4/, last access 9 August 2021.

Another explanation from this difference could be the difference in radar penetration factor for the Ku-band and Ka-band over MYI and FYI, as suggested by Armitage and Ridout [46]. The radar penetration factor describes the radar dominant scattering horizon in relation to the snow and ice surfaces, such that a value of zero indicates that the airsnow interface is the dominant scattering horizon, and a value of one will indicate that the ice-snow interface is more dominant. Based on their results, the Ku-band not only shows a stronger dominance of the ice-snow interface in their results but also a higher variance in radar penetration factor depending on MYI and FYI. In comparison, the Kuband shows a radar penetration factor around 0.5 for both sea ice types, suggesting a somewhat equal measure of dominance from both interfaces but almost no difference in radar penetration factor depending on the type (FYI vs. MYI). This factor may also play a role in the classification of sea ice types since the penetration factor seems to be more ice-type-dependent in the Ku-band than Ka-band.

\subsection{Uncertainty in Validation Data}

The ultimate goal is to achieve a sea ice type classification that covers the entire Arctic Ocean, and we use the availability of daily sea ice type products from OSI SAF providing information over the entire Arctic Ocean as reference data sets. OSI SAF's sea ice type product is based on a combination of passive microwave data (SSMIS and Advanced Microwave Scanning Radiometer-2 (AMSR2)) and active microwave scatterometer data 
(ASCAT), and the product is validated by ice charts and SAR images [26,47]. As it is well validated and no additional ice product is believed to have better accuracy [47], we assume this to be reliable ground truth. Prior studies (e.g., $[17,27,28]$ ) have used Arctic and Antarctic Research Institute (AARI) ice charts that also provide information on sea ice types on an Arctic-wide scale, but there have been no reports discussing the accuracy of AARI charts yet [28].

However, we want to highlight that even though OSI SAF's sea ice type product is well validated, studies have shown a discrepancy between the ice type edge distinguishing FYI and MYI ice in the OSI SAF product with the ice type edge estimated from extensive in situ data of sea ice collected in April 2017 by Haas et al. [48]. The ice type edge between FYI and MYI estimated from Haas et al. [48] is based on in situ observations and comparisons with SAR imagery. Here, they conclude that there is a disagreement between the locations of the ice type boundaries, which demonstrates the importance of ongoing validation of OSI SAF products. Furthermore, it also highlights the importance of an improved understanding of the effects of mixed ice types and product resolution. Based on their findings, the disagreement between the ice types estimated by us from AltiKa radar echoes and the OSI SAF ice types may not only be due to AltiKa's limited penetration capabilities and, thus, it was not possible to extract subsurface information that can aid the discrimination of sea ice types. On the other hand, the method chosen could be a result of the OSI SAF ice type product not being the perfect ground truth and the MYI/FYI border being different from what OSI SAF shows. Our results show that more ice is misclassified as FYI than MYI, and the results of Haas et al. [48] shows the ice border between FYI and MYI to be located further into the MYI area than suggested by the OSI SAF product. This suggests that the OSI SAF product may be overestimating the coverage of MYI ice. Thus, this study also encourages more work into the validation of the OSI SAF sea ice type product.

Furthermore, the comparison of the spatial distribution of sea ice and open ocean based on LEW shows the possibility of estimating the ice edge by using observations of LEW from AltiKa (Figure 6). Thus, we encourage the use of LEW to estimate sea ice edge and to make comparisons with, e.g., OSI SAF, in order to investigate the use of altimetry as additional reference data for sea ice edge detection.

\subsection{Study Area and Training Data Selection}

When investigating the spatial distribution of MAX, $\sigma_{0}$, and LEW (Figure 6), it is clear that parts of the MYI ice cover are not easily distinguishable in the data; it looks similar to FYI than compared to MYI. This was not directly taken into account when selecting training datasets/study areas, which are chosen mainly as the older, mostly deformed MYI ice north-west of Greenland and the newer, smoother FYI near the Laptev Sea. Thus, the threshold-based classifiers and the supervised classifiers are assuming that MYI includes only highly deformed surfaces and FYI includes only very smooth surfaces. However, this is not necessarily the case, as shown by the spatial distribution (Figure 6). FYI can be deformed due to ice drift caused by the wind and currents, and MYI may appear smoother, which can be caused by, e.g., surface melt, resulting in the misclassification of Ka-band radar altimetry waveforms. Future work should include several training data sites that include several types of MYI and FYI ice, respectively.

\subsection{Copernicus Polar Ice and Snow Topography Altimeter (CRISTAL) Mission and Future Work}

One of the High Priority Candidate Missions (HPCMs) of the Copernicus Programme at ESA is the Copernicus Polar Ice and Snow Topography Altimeter (CRISTAL), which will carry a dual-frequency ( $\mathrm{Ku}$ and $\mathrm{Ka}$ ) band radar altimeter [11]. The main driver for CRISTAL including the Ka-band is the retrieval of snow thickness on sea ice, which is one of the mission requirements. Nonetheless, the dual-frequency measurement may prove valuable for ice classification too. As discussed earlier, there are previous studies akin to ours for Ku-band altimeters, both airborne and satellite. However, our study here is the first-ever to show Ka-band satellite altimeter waveform characteristic distributions over different 
ice types. This is the first step for the CRISTAL ice type classification algorithms, which we foresee using both $\mathrm{Ku}$-band and Ka-band to improve the classification skill from that of CryoSat-2. However, our study here already shows that AltiKa achieves classification skills comparable to that of CryoSat-2 for FYI, even if the spatial resolution of CryoSat-2 (delay-Doppler altimeter) is significantly better than the pulse-limited AltiKa.

Existing CryoSat-2 and AltiKa data-even if not temporally coincident-should allow for the development of the first dual-frequency ice classification algorithms applicable to CRISTAL. Thus, for future work, we would suggest combining Ku-waveforms and Ka-waveforms over stable ice by using, for example, satellite SAR data as a reference. SAR data could provide much more accurate descriptions of the ice cover than the OSI SAF product used here, since specific surface characteristics are recognisable and the spatial resolution is higher for SAR. However, at the scale of few kilometres, any latency will complicate the analysis. Regardless, CRISTAL mission will undoubtedly benefit from the best possible understanding of gained value from combining Ku-waveforms and Kawaveforms. Especially with the CRISTAL instrument providing Ka-observations and $\mathrm{Ku}$-observations as a delay-doppler (SAR) altimeter, increasing the resolution of both Ka-band and Ku-band will allow additional waveform parameters (such as SSD) to be used in the classification, which have shown very useful for the sea ice type classification using CryoSat-2.

\section{Conclusions and Reflections}

In this study, we investigated classifying sea ice types in the Arctic by AltiKa Ka-band radar altimeter data, exploiting the fact that the radar echo shapes retrieved from FYI and MYI are different. We investigated the radar echoes from AltiKa by using four different classifiers that are previously used for the same purpose on Ku-band data. The classifiers were the following: a threshold-based classification, which estimates classification intervals (modal value $\pm s t d$ ) of the extracted waveform parameters retrieved from two areas dominated by either FYI or MYI; and three supervised classifiers-Random Forest (RF), Bayesian and $k$-nearest neighbour (KNN). For AltiKa, MAX and $\sigma_{0}$ proved most suitable as classifying parameters (based on qualitative analysis of distributions, CDF's and maximal distance calculated by the two-sample KS-test). The threshold-based classification was on average able to correctly classify (performance based on 35 day cycle in years 20142018) $65.23 \%$ as FYI and $39.30 \%$ as MYI using a combination of MAX and $\sigma_{0}$ as classifying parameters. When using only MAX and $\sigma_{0}$ as classifying parameters, some information on the outer extent of MYI, e.g., the Beaufort Sea, was misclassified as FYI. The KS-test also showed LEW to be a useful classification parameter, but it could not be applied in the threshold-based classification due to overlap in the thresholds. However, the spatial distribution of LEW showed great promise of using LEW to separate sea ice and ocean to support sea ice edge masks for the ice thickness algorithm. Hence, further studies using LEW from Ka-band measurements to estimate the sea ice edge are encouraged, especially as an additional validation source for the OSI SAF sea ice edge. When investigating the supervised classifiers, which have proved valuable in past studies on Ku-band based on averaged classification performances, the combination of LEW $+\sigma_{0}$ proved highest when training the data (applying same study area data as used in the threshold-based classification, as training data). It showed an overall performance of $92.82 \%$ (FYI) and $27.03 \%$ (MYI) with Bayesian; $91.27 \%$ (FYI) and 34.07\% (MYI) with KNN; and 91.85\% (FYI) and $33.24 \%$ (MYI) with RF. The classification performance for MYI is low overall, and most of the ice cover is classified as FYI rather than MYI. Using training data from smoother MYI ice could improve the classification performance of MYI, however, this is likely to decrease the performance of FYI as well since FYI could be misclassified as MYI.

For any classifier, training data are of utmost importance. We have currently used the sea ice north-west of Greenland (MYI) and near the Laptev Sea (FYI); however, the data may not be sufficiently describing all the types of sea ice roughness that occurs within both 
MYI and FYI and the mixing of these sea ice types. Thus, we encourage future studies to investigate other training datasets to study if that improves the classification.

Since LEW, MAX and $\sigma_{0}$ are the classifying parameters used and they mostly provide information about roughness due to the limited penetrating capabilities of the Ka-band, it suggests that while Ka-band can be used to discriminate between flat (smooth) and deformed surfaces, it cannot discriminate properly between deformed FYI and MYI in itself. Using other waveform parameters (such as TES/TEW) could provide additional information about the surface (e.g., snow properties which are usually different over MYI and FYI), but since the Ka-band does not penetrate extensively into the snowpack, this information appears to be lost.

However, the future ESA High Priority Candidate mission CRISTAL utilises a dualfrequency altimeter (Ka-band and Ku-band), which could provide useful information on sea ice types and discrimination between sea ice and ocean to improve sea ice edge masks, e.g., by using waveform parameter LEW, as AltiKa has shown it as a possible option. Furthermore, the Synthetic Aperture Radar (SAR) Ku-band altimeter that CRISTAL will also carry is similar to the altimeter of CryoSat-2, where prior studies have shown great success in discriminating between sea ice types. Combining the Ka-band and Ku-band waveform parameters and using this combination for discriminating the sea ice types could become interesting future investigations in the case of observing just how much information can be retrieved from the surface-sensitive Ka-band and the fact that the Ku-band that can penetrate relatively far into the snowpack. In particular, the work on estimating less deformed MYI and/or rougher FYI by combining Ka/Ku-band data is encouraged.

Author Contributions: Conceptualization, R.M.F.H., E.R. and H.S.; formal analysis, R.M.F.H.; investigation, R.M.F.H., E.R. and H.S.; methodology, R.M.F.H., E.R. and H.S.; software, R.M.F.H.; supervision, H.S.; validation, R.M.F.H., E.R. and H.S.; visualization, R.M.F.H.; writing-original draft, R.M.F.H.; writing-review and editing, R.M.F.H., E.R. and H.S. All authors have read and agreed to the published version of the manuscript.

Funding: This research received no external funding.

Institutional Review Board Statement: Not applicable.

Informed Consent Statement: Not applicable.

Data Availability Statement: AltiKa (Geophysical Data Records; GDR) data are available from AVISO (https: / / www.aviso.altimetry.fr/en/home.html, last access 11 April 2017) and the OSI SAF Sea Ice Type (OSI-403-c) data are available from EUMETSAT OSI SAF website (http: / /www.osi-saf. org/, last access 16 April 2019). All supervised classifiers constructed for this study were made using the MATLAB Statistics and Machine Learning Toolbox ${ }^{\mathrm{TM}}$.

Acknowledgments: We would like to thank AVISO for providing the AltiKa GDR data and OSI SAF (EUMETSAT) for providing the sea ice type product. We thank Heidi Sallila at FMI for valuable comments and remarks that improved this work.

Conflicts of Interest: The authors declare no conflict of interest.

\section{Appendix A}

The threshold-based classifications of the sea ice types based on MAX, $\sigma_{0}$ and a combination of MAX and $\sigma_{0}$ are shown in Figure A1. Generally, it follows the distribution already shown in Figure 6. In all the years, the threshold-based classifications are missing MYI features in the Beaufort Sea, which is most pronounced in 2014 and 2015, and the MYI extent is not well determined. In both 2015 and 2018, the classification seems to overestimate the amount of MYI near the East Siberian Sea. When investigating the performance of the classification (by Equation (3)), it is clear that less than $50 \%$ of the AltiKa MYI data points are classified correctly according to the reference data, see Table A1. 
Table A1. Data for classification over the Arctic. Classification accuracy (\%) shows how much has been correctly classified when comparing with validation data from OSI SAF. Number of echoes used: 3,551,399 (2014), 3,899,013 (2015), 4,009,484 (2016), 3,682,174 (2017) and 3,620,388 (2018). The overall highest classification performances of correctly classified FYI and MYI are highlighted in bold.

\begin{tabular}{|c|c|c|c|c|c|c|c|c|}
\hline \multirow[b]{3}{*}{ Year } & \multicolumn{8}{|c|}{ MAX } \\
\hline & \multicolumn{4}{|c|}{ MYI } & \multicolumn{4}{|c|}{ FYI } \\
\hline & MYI & FYI & No class & Ambiguous & MYI & FYI & No class & Ambiguous \\
\hline 2014 & 31.26 & 62.79 & 1.46 & 4.49 & 19.14 & 73.98 & 1.36 & 5.52 \\
\hline 2015 & 31.91 & 56.28 & 3.99 & 7.82 & 17.05 & 79.66 & 0.67 & 2.62 \\
\hline 2016 & 39.10 & 42.19 & 5.98 & 12.73 & 20.35 & 74.60 & 1.53 & 3.52 \\
\hline 2017 & 40.62 & 43.11 & 4.77 & 11.50 & 28.23 & 67.73 & 10.57 & 3.57 \\
\hline 2018 & 42.08 & 49.05 & 1.94 & 6.93 & 18.24 & 61.47 & 15.16 & 5.13 \\
\hline \multirow[t]{3}{*}{ Mean } & 37.00 & 50.68 & 3.63 & 8.69 & 18.58 & 71.49 & 5.86 & 4.07 \\
\hline & \multicolumn{8}{|c|}{$\sigma_{0}$} \\
\hline & \multicolumn{4}{|c|}{ MYI } & \multicolumn{4}{|c|}{ FYI } \\
\hline Year & MYI & FYI & No class & Ambiguous & MYI & FYI & No class & Ambiguous \\
\hline 2014 & 38.55 & 54.13 & 1.57 & 5.74 & 35.28 & 58.18 & 1.08 & 5.46 \\
\hline 2015 & 35.30 & 15.12 & 4.14 & 8.44 & 18.61 & 66.16 & 11.93 & 3.31 \\
\hline 2016 & 42.51 & 39.56 & 5.45 & 12.48 & 28.68 & 66.28 & 1.26 & 3.75 \\
\hline 2017 & 43.56 & 41.76 & 4.06 & 10.62 & 19.73 & 66.19 & 10.40 & 3.68 \\
\hline 2018 & 43.71 & 47.75 & 1.87 & 6.67 & 20.18 & 59.60 & 15.26 & 5.56 \\
\hline \multirow[t]{3}{*}{ Mean } & 40.73 & 39.66 & 3.42 & 8.79 & 24.49 & 63.16 & 7.99 & 4.36 \\
\hline & \multicolumn{8}{|c|}{$\operatorname{MAX}+\sigma_{0}$} \\
\hline & \multicolumn{4}{|c|}{ MYI } & \multicolumn{4}{|c|}{ FYI } \\
\hline Year & MYI & FYI & No class & Ambiguous & MYI & FYI & No class & Ambiguous \\
\hline 2014 & 37.59 & 56.81 & 1.46 & 4.14 & 34.23 & 60.31 & 0.93 & 4.53 \\
\hline 2015 & 33.74 & 54.40 & 4.02 & 7.83 & 17.28 & 68.41 & 4.70 & 9.61 \\
\hline 2016 & 41.74 & 40.80 & 5.82 & 11.64 & 26.77 & 68.67 & 1.39 & 3.17 \\
\hline 2017 & 40.93 & 43.64 & 4.71 & 10.72 & 18.20 & 67.90 & 10.55 & 3.35 \\
\hline 2018 & 50.70 & 39.94 & 1.52 & 7.84 & 23.79 & 56.56 & 14.84 & 4.81 \\
\hline Mean & 39.30 & 49.02 & 3.58 & 8.10 & 23.02 & 65.23 & 6.58 & 5.17 \\
\hline
\end{tabular}

When the classification is based on MAX only, the classification performance for MYI is on average $37.00 \%$ (within ranges of $31.26-42.08 \%$ ); for $\sigma_{0}$ these numbers are $40.73 \%$ (35.30-43.71\%); and for the combination of MAX and $\sigma_{0}$, it is $39.30 \%(33.74-50.70 \%)$. The classification accuracies of FYI are significantly higher, with an average (range) classification of $71.49 \%(61.47-79.66 \%)$ for MAX; 63.16\% (58.18-66.28\%) for $\sigma_{0}$; and $65.23 \%(56.56-68.67 \%)$ for the combination of MAX and $\sigma_{0}$. It is clear that MAX is significantly better for estimating FYI, while $\sigma_{0}$ allows for the overall better detection of MYI. Therefore, a combination of both parameters should in principle provide the overall best classification of both MYI and FYI. However, the classification by threshold shows quite low performance for MYI and thus suggests that these two parameters cannot be used in their own capacity to identify sea ice types with an accuracy higher than about $\sim 70 \%$ for FYI and about $\sim 40 \%$ for MYI. Some sea ice type information is lost when only using surface roughness parameters MAX and $\sigma_{0}$ as inputs. It may be that the information is lost when ice types look similar from a radar point of view. 
OSI SAF
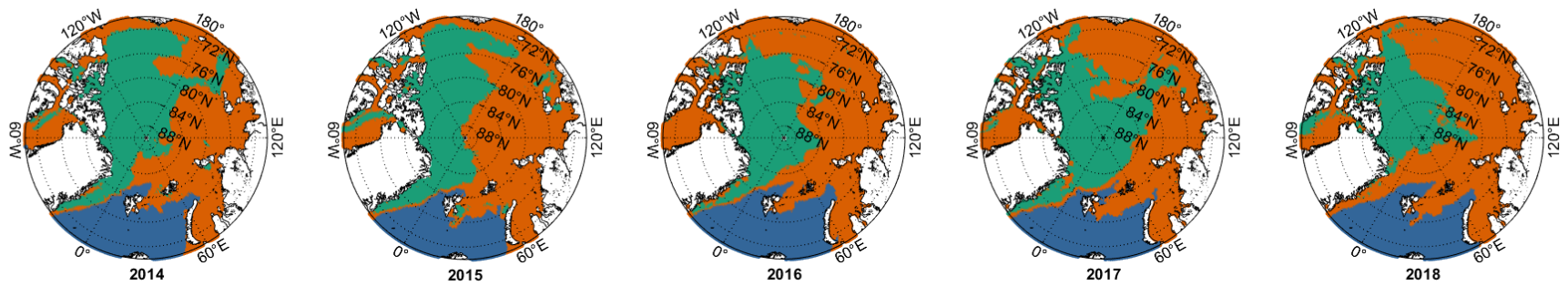

MAX
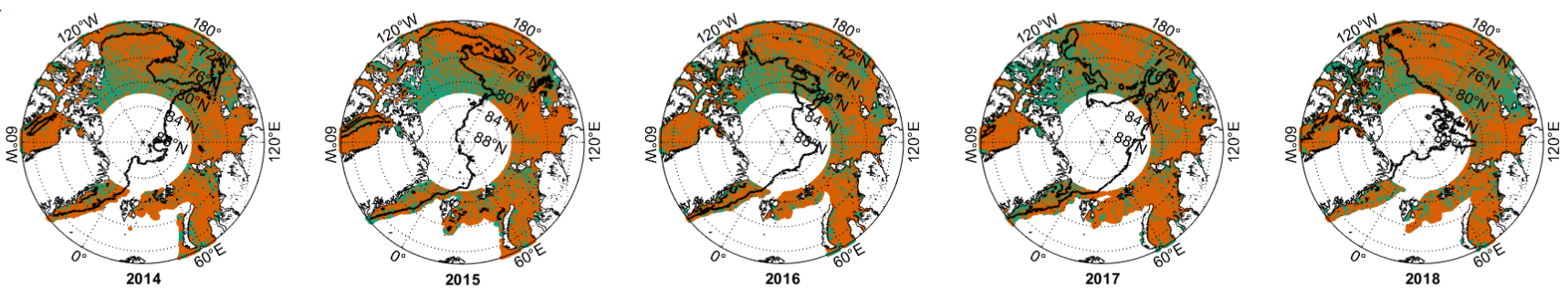

Backscatter
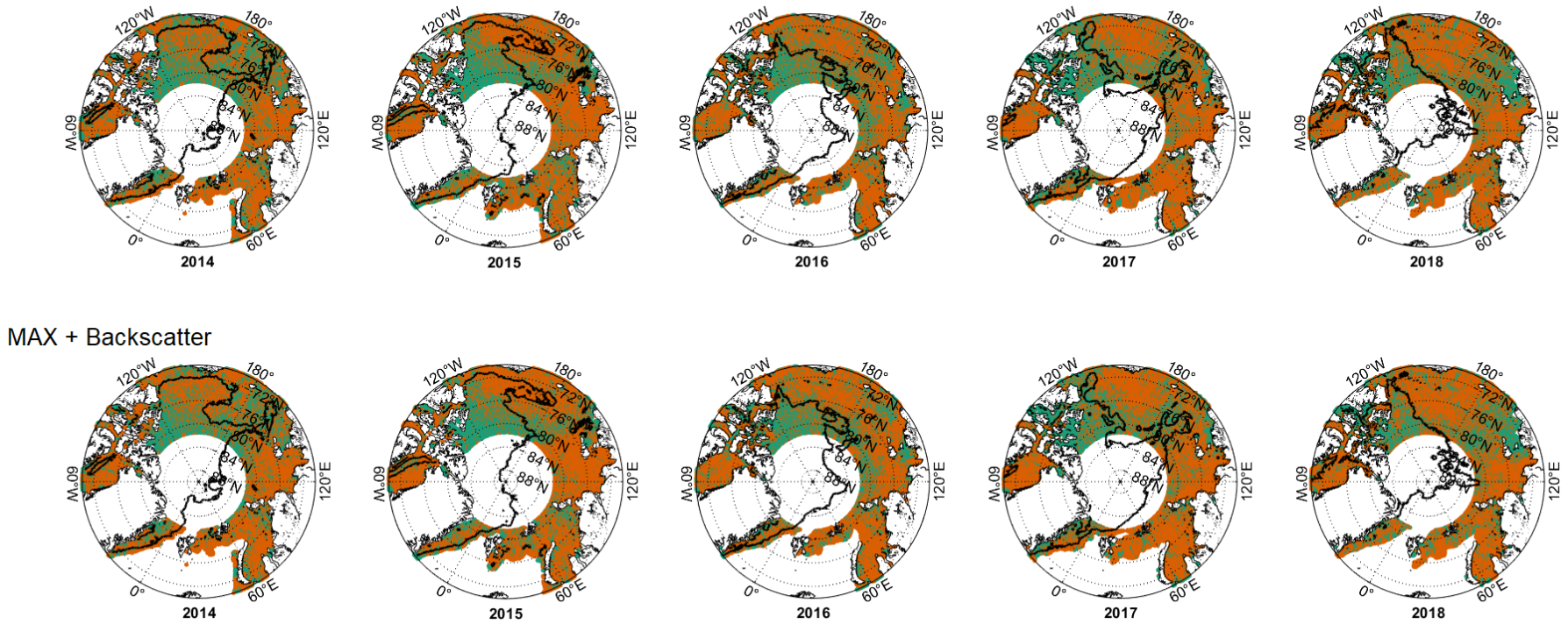

Figure A1. Ice-type charts from February 2014 to 2018. (Top) OSI SAF data without a polar gap of AltiKa applied, (bottom three) AltiKa data classified by intervals from Table 3 in the order of MAX, $\sigma_{0}$ (backscatter) and a combination of both MAX and $\sigma_{0}$. The charts are classified as follows: open water (blue), FYI (brown) and MYI (green). Ambiguous values and no class values are not depicted. The black line denotes MYI/FYI ice edge from OSI SAF (in row 2-4).

\section{References}

1. Ricker, R.; Hendricks, S.; Helm, V.; Gerdes, R. Classification of CryoSat-2 radar echoes. In Towards an Interdisciplinary Approach in Earth System Science; Lohmann, G., Meggers, H., Unnithan, V., Wolf-Gladrow, D., Notholt, J., Bracher, A., Eds.; Springer International Publishing: Cham, Switzerland, 2015; Volume 38. [CrossRef]

2. AMAP. Arctic Climate Change Update 2021: Key Trends and Impacts; Technical Report; AMAP Secretariat, The Fram Centre, University of Zurich: Tromsø, Norway, 2021.

3. Serreze, M.C.; Barrett, A.P.; Stroeve, J.C.; Kindig, D.N.; Holland, M.M. The emergence of surface-based Arctic amplification. Cryosphere 2009, 3, 11-19. [CrossRef]

4. AMAP. Arctic Climate Issues 2011: Changes in Arctic Snow, Water, Ice and Permafrost; Swipa 2011, Overview Report; Arctic Monitoring and Assessment Programme (AMAP): Oslo, Norway, 2012; p. 97.

5. Müller-Stoffels, M.; Wackerbauer, R. Regular network model for the sea ice-albedo feedback in the Arctic. Chaos $2011,21$. [CrossRef] 
6. Rothrock, D.A.; Yu, Y.; Maykut, G.A. Thinning of the Arctic sea-ice cover. Geophys. Res. Lett. 1999, 26, 3469-3472. [CrossRef]

7. Rothrock, D.A.; Percival, D.B.; Wensnahan, M. The decline in arctic sea-ice thickness: Separating the spatial, annual, and interannual variability in a quarter century of submarine data. J. Geophys. Res. Ocean. 2008, 113. [CrossRef]

8. Haas, C.; Gerland, S.; Eicken, H.; Miller, H. Comparison of sea-ice thickness measurements under summer and winter conditions in the Arctic using a small electromagnetic induction device. Geophysics 1997, 62, 749-757. [CrossRef]

9. Hendricks, S.; Gerland, S.; Smedsrud, L.H.; Haas, C.; Pfaffhuber, A.A.; Nilsen, F. Sea-ice thickness variability in Storfjorden, Svalbard. Ann. Glaciol. 2011, 52, 61-68. [CrossRef]

10. Quartly, G.D.; Rinne, E.; Passaro, M.; Andersen, O.B.; Dinardo, S.; Fleury, S.; Guillot, A.; Hendricks, S.; Kurekin, A.A.; Müller, F.L.; et al. Retrieving Sea Level and Freeboard in the Arctic: A Review of Current Radar Altimetry Methodologies and Future Perspectives. Remote Sens. 2019, 11, 881. [CrossRef]

11. Kern, M.; Cullen, R.; Berruti, B.; Bouffard, J.; Casal, T.; Drinkwater, M.R.; Gabriele, A.; Lecuyot, A.; Ludwig, M.; Midthassel, R.; et al. The Copernicus Polar Ice and Snow Topography Altimeter (CRISTAL) high-priority candidate mission. Cryosphere 2020, 14, 2235-2251. [CrossRef]

12. Markus, T.; Neumann, T.; Martino, A.; Abdalati, W.; Brunt, K.; Csatho, B.; Farrell, S.; Fricker, H.; Gardner, A.; Harding, D.; et al. The Ice, Cloud, and land Elevation Satellite-2 (ICESat-2): Science requirements, concept, and implementation. Remote Sens. Environ. 2017, 190, 260-273. [CrossRef]

13. Wernecke, A.; Kaleschke, L. Lead detection in Arctic sea ice from CryoSat-2: Quality assessment, lead area fraction and width distribution. Cryosphere 2015, 9, 1955-1968. [CrossRef]

14. Zakharova, E.A.; Fleury, S.; Guerreiro, K.; Willmes, S.; Rémy, F.; Kouraev, A.V.; Heinemann, G. Sea Ice Leads Detection Using SARAL/AltiKa Altimeter. Mar. Geod. 2015, 38, 522-533. [CrossRef]

15. Zygmuntowska, M.; Khvorostovsky, K.; Helm, V.; Sandven, S. Waveform classification of airborne synthetic aperture radar altimeter over Arctic sea ice. Cryosphere 2013, 7, 1315-1324. [CrossRef]

16. Tilling, R.L.; Ridout, A.; Shepherd, A. Estimating Arctic sea ice thickness and volume using CryoSat-2 radar altimeter data. Adv. Space Res. 2018, 62, 1203-1225. [CrossRef]

17. Rinne, E.; Similä, M. Utilisation of CryoSat-2 SAR altimeter in operational ice charting. Cryosphere 2016, 10, 121-131. [CrossRef]

18. Dwyer, R.; Godin, R. Determining Sea-Ice Boundaries and Ice Roughness Using GEOS-3 Altimeter Data; NASA Contractor Report 156862; NASA: Washington, DC, USA, 1980.

19. Onstott, R.; Grenfell, T.; Matzler, C.; Luther, C.; Svendsen, E. Evolution of microwave sea ice signatures during early summer and midsummer in the marginal ice zone. J. Geophhys. Res. 1987, 92, 6825-6835. [CrossRef]

20. Fedor, L.S.; Hayne, G.S.; Walsh, E.J. Ice-type Classifications From Airborne Pulse-limited Radar Altimeter Return Waveform Characteristics. In Proceedings of the 12th Canadian Symposium on Remote Sensing Geoscience and Remote Sensing Symposium, Vancouver, BC, Canada, 10-14 July 1989; Volume 3, pp. 1949-1952.

21. Fetterer, F. Sea ice altimetry. In Microwave Remote Sensing of Sea Ice; Geophysical Monograph Series; American Geophysical Union: Washington, DC, USA, 1992; Volume 68, Chapter 7, pp. 11-135.

22. Chase, J.; Holyer, R. Estimation of sea ice type and concentration by linear unmixing of Geosat altimeter waveforms. J. Geophys. Res. 1990, 95, 18015-18018. [CrossRef]

23. Drinkwater, M. Ku band airborne radar altimeter observations of marginal sea ice during the 1984 marginal ice zone experiment. J. Geophys. Res. 1991, 96, 4555-4572. [CrossRef]

24. Laxon, S. Sea ice extent mapping using the ERS-1 radar altimeter. EARSeL Adv. Remote Sens. 1994, 3, 112-115.

25. Peacock, N.R.; Laxon, S.W. Sea surface height determination in the Arctic Ocean from ERS altimetry. J. Geophys. Res. Ocean 2004, 109. [CrossRef]

26. Zygmuntowska, M. Arctic Sea Ice Altimetry-Advances and Current Uncertainties. Ph.D. Thesis, Department of Geophysics, University of Bergen, Bergen, Norway, 2014.

27. Shen, X.; Zhang, J.; Meng, J.; Ke, C.Q. Sea ice type classification based on random forest machine learning with Cryosat-2 altimeter data. In Proceedings of the 2017 International Workshop on Remote Sensing with Intelligent Processing (RSIP), Shanghai, China, 18-21 May 2017; pp. 1-5.

28. Shu, S.; Zhou, X.; Shen, X.; Liu, Z.; Tang, Q.; Li, H.; Ke, C.; Li, J. Discrimination of different sea ice types from CryoSat-2 satellite data using an Object-based Random Forest (ORF). Mar. Geod. 2020, 43, 213-233. [CrossRef]

29. Nolin, A.W.; Mar, E. Artic Sea Ice Roughness Estimated from Multi-Angular Reflectance Satellite Imagery. Remote Sens. 2018, 11, 50. [CrossRef]

30. Verron, J.; Sengenes, P.; Lambin, J.; Noubel, J.; Steunou, N.; Guillot, A.; Picot, N.; Coutin-Faye, S.; Sharma, R.; Gairola, R.M.; et al. The SARAL/AltiKa Altimetry Satellite Mission. Mar. Geod. 2015, 38, 2-21. [CrossRef]

31. Maheshwari, M.; Mahesh, C.; Rajkumar, K.; Pllipad, J.; Rajak, D.R.; Oza, S.; Kumar, R.; Sharma, R. Estimation of Sea Ice Freeboard from SARAL/AltiKa Data. Mar. Geod. 2015, 38, 487-496. [CrossRef]

32. Bonnefond, P.; Veeron, J.; Aublanc, J.; Babu, K.N.; Bergé-Nguyen, M.; Cancet, M.; Chaudhary, A.; Crétaux, J.; Frappart, F.; Harris, B.J.; et al. The Benefits of the Ka-Band as Evidenced from the SARAL/AltiKa Altimetric Mission: Quality Assement and Unique Characteristics of AltiKa Data. Remote Sens. 2018, 10, 83. [CrossRef]

33. Rajkumar, K.S.; Maheshwari, M.; Pallipad, J.; Rajak, D.R.; Kumar, R.; Oza, S.R. Concurrent Use of OSCAT and AltiKa to Characterize Antarctic Ice Surface Features. Mar. Geod. 2015, 38, 497-509. [CrossRef] 
34. The European Organisation for the Exploitation of Meteorological Satellites (EUMETSAT). HL OSI SAF products-Sea Ice Type Maps. 2019. Available online: http:/ / osisaf.met.no/p/ice/ (accessed on 28 February 2019).

35. The European Organisation for the Exploitation of Meteorological Satellites (EUMETSAT). Sea Ice Edge (OSI-402) and Sea Ice Type (OSI-403). 2019. Available online: http://osisaf.met.no/p/ice/edge_type_long_description.html (accessed on 28 February 2019).

36. Legresy, B.; Papa, F.; Remy, F.; Vinay, G.; van den Bosch, M.; Zanife, O. ENVISAT radar altimeter measurements over continental surfaces and ice caps using the ICE-2 retracking algorithm. Remote Sens. Environ. 2005, 95, 150-163. [CrossRef]

37. CNES. SARAL/AltiKa Products Handbook; Centre National d'Études Spatiales (CNES): Paris, France, 2013 ; p. 86.

38. Lawrence, I.R.; Tsamados, M.C.; Stroeve, J.C.; Armitage, T.W.K.; Ridout, A.L. Estimating snow depth over Arctic sea ice from calibrated dual-frequency radar freeboards. Cryosphere 2018, 12, 3551-3564. [CrossRef]

39. Stroeve, J.; Nandan, V.; Willatt, R.; Tonboe, R.; Hendricks, S.; Ricker, R.; Mead, J.; Mallett, R.; Huntemann, M.; Itkin, P.; et al. Surface-based Ku- and Ka-band polarimetric radar for sea ice studies. Cryosphere 2020, 14, 4405-4426. [CrossRef]

40. Hanson, R.; Stutz, J.; Cheeseman, P. Bayesian Classification Theory; Technical Report FIA-90-12-7-01; NASA Ames Research Center, Artificial Intelligence Research Branch: Mountain View, CA, USA, 1991.

41. Tonboe, R.; Andersen, S.; Pedersen, L. Simulation of the Ku-band Radar altimeter sea ice effective scattering surface. IEEE Geosci. Remote Sens. Lett. 2006, 3, 237. [CrossRef]

42. Blanchard-Wrigglesworth, E.; Farrell, S.L.; Newman, T.; Bitz, C.M. Snow cover on Arctic sea ice in observations and an Earth System Model. Geophys. Res. Lett. 2015, 42, 10342-10348. [CrossRef]

43. Guerreiro, K.; Fleury, S.; Zakharova, E.; Rémy, F.; Kouraev, A. Potential for estimation of snow depth on Arctic sea ice from CryoSat-2 and SARAL/AltiKa missions. Remote Sens. Environ. 2016, 186, 339-349. [CrossRef]

44. King, J.; Skourup, H.; Hvidegaard, S.M.; Rosel, A.; Gerland, S.; Spreen, G.; Polashenski, C.; Helm, V.; Liston, G.E. Comparison of freeboard retrieval and ice thickness calculation from ALS, ASIRAS, and CryoSat-2 in the Norwegian Arctic to field measurements made during the N-ICE2015 expedition. J. Geophys. Res. Ocean. 2018, 123, 1123-1141. [CrossRef]

45. Vincent, P.; Steunou, N.; Caubetq, E.; Phalippou, L.; Rey, L.; Thouvenot, E.; Verron, J. AltiKa: A Ka-band Altimetry Payload and System for Operational Altimetry during the GMES Period. Sensors 2006, 6, 208-234. [CrossRef]

46. Armitage, T.W.K.; Ridout, A.L. Arctic sea ice freeboard from AltiKa and comparison with CryoSat-2 and Operation IceBridge. Geophys. Res. Lett. 2015, 42, 6724-6731. [CrossRef]

47. Aaboe, S.; Breivik, L.-A.; Sørensen, A.; Eastwood, S.; Lavergne, T. Global Sea Ice Edge and Type Product User's Manual OSI-402-c E OSI-403-c; Version 2.3; EUMETSAT OSISAF (MET Norway): Oslo, Norway, 2018.

48. Haas, C.; Beckers, J.; King, J.; Silis, A.; Stroeve, J.; Wilkinson, J.; Notenboom, B.; Schweiger, A.; Hendricks, S. Ice and Snow Thickness Variability and Change in the High Arctic Ocean Observed by In Situ Measurements. Geophys. Res. Lett. 2017, 44, 10462-10469. [CrossRef] 